\title{
Assessing the usage and level-of-service of pedestrian facilities in train stations: A Swiss case study
}

\author{
Flurin S. Hänseler* \\ Michel Bierlaire* \\ Riccardo Scarinci*
}

April 2, 2016

\begin{abstract}
A framework for assessing the usage and level-of-service of rail access facilities is presented. It consists of two parts. A dynamic demand estimator allows to obtain time-dependent pedestrian origin-destination demand within walking facilities. Using that demand, a traffic assignment model describes the propagation of pedestrians through the station, providing an estimate of prevalent traffic conditions in terms of flow, walking times, speed and density. The corresponding level-of-service of the facilities can be directly obtained. The framework is discussed at the example of Lausanne railway station. For this train station, a rich set of data sources including travel surveys, pedestrian counts and trajectories has been collected in collaboration with the Swiss Federal Railways. Results show a good performance of the framework. To underline its practical applicability, a six-step planning guideline is presented that can be used to design and optimize rail access facilities for new or existing train stations. In the long term, the framework

${ }^{*}$ Transport and Mobility Laboratory, School of Architecture, Civil and Environmental Engineering, École Polytechnique Fédérale de Lausanne, Switzerland
\end{abstract}


may also be used for crowd management, involving real-time monitoring and control of pedestrian flows.

\section{Introduction}

Passenger railway systems around the world are undergoing a significant growth. In the last decade, the number of transported passengers in Europe and North America has increased by about 3\% annually (Puentes et al., 2013; Kasparick, 2010; Amacker, 2012), while in Asia even two-digit growth rates have been observed (Chung, 2012; LTA Singapore, 2012). Partially in response to that growth, and partially inducing it, the frequency and capacity of trains have been continuously expanded (Kallas, 2014).

In the context of that expansion, rail access facilities have largely been neglected (Schneider, 2012). Rail access facilities include pedestrian walkways, waiting areas or platforms, and in the broader sense all pedestrian infrastructures within a train station. Today, these facilities are gaining attention as pedestrian congestion is becoming a common phenomenon (Ganansia et al., 2014; Hermant, 2012), waiting space on platforms and in station halls is getting scarce (Hoogendoorn and Daamen, 2004), expectations in terms of comfort and shopping opportunities are growing (Nio, 2012), or safety regulations are violated (Buchmüller and Weidmann, 2008).

To optimize the design and operation of rail access facilities, there is a general need to better understand the usage of railway stations by pedestrians (Parkinson and Fisher, 1996). Such knowledge is essential for the adequate dimensioning of infrastructures, such as the width of an underground walkway or the area of a platform. It is also beneficial for an efficient operation of a train station. For instance, should trains with a particularly large ridership be served only by certain platforms, and should the simultaneous arrival of large trains be avoided? How long should transfer times be to allow for sufficient time to reach a connecting train? Which are the optimal walking routes during normal operation and in case of extreme events? Where should sales and service points be located to attract a maximum of walk-in customers?

A way of addressing such questions is by developing a quantitative, spatio-temporal understanding of pedestrian flows. This information can 
then be used to tackle the mentioned problems, which are often subject to financial, operational, political and legal constraints.

In this article, we present a modeling framework that provides an estimate of pedestrian origin-destination (OD) demand and is able to assess the level-of-service (LOS) of an infrastructure. Figure 1 provides a graphical representation of that framework, considering various data sources, a demand estimator and a traffic assignment model. These elements are discussed one by one in the subsequent sections. In the last section, they are set in a general context, enriched by practical guidelines.

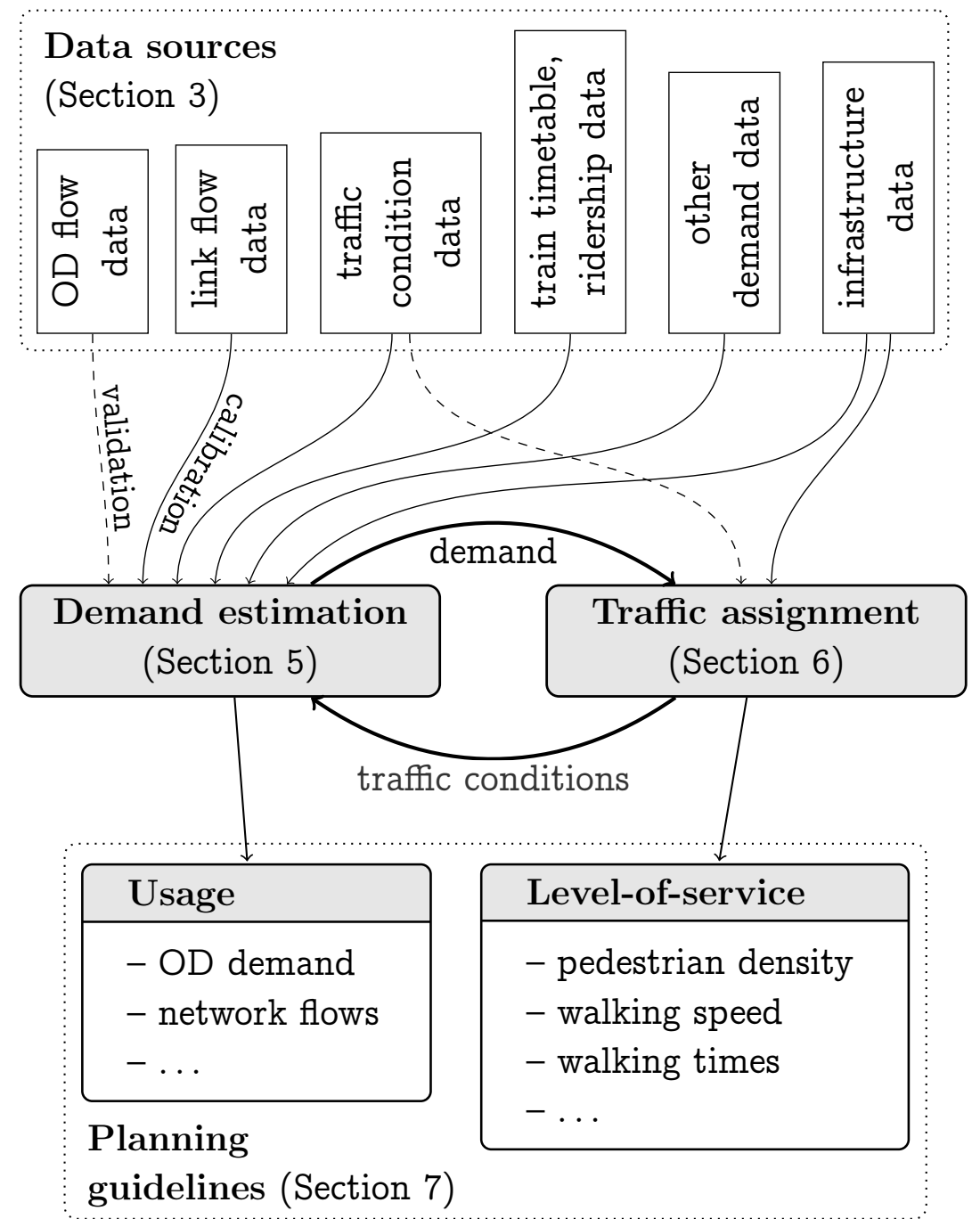

Figure 1: Framework for estimating the usage and level-of-service of rail access facilities. 
Throughout this article, reference is made to the railway station of Lausanne, which we have studied together with the Swiss Federal Railways (SBB) between 2011 and 2015. Lausanne railway station is the largest node in the railway network of Western Switzerland, serving 650 arriving and departing trains on weekdays (Amacker, 2012). The station has reached capacity in the year 2010, and a doubling of passenger demand is expected by 2030. About $€ 450,000$ have been invested in a pedestrian tracking system to monitor pedestrian movements on central walkways, to which this thesis has access. In total, $€ 1.1$ billion is spent between 2010 and 2020 to enlarge the station, preparing it for future growth.

At the example of that case study, we investigate whether the proposed framework can provide an accurate understanding of the usage and level-of-service of pedestrian facilities. We thereby concentrate on walking areas, as for platforms already reliable dimensioning guidelines exist (Buchmüller and Weidmann, 2008). The analysis concentrates on the understanding of the status quo for two reasons. First, a validation can be made based on real data. Second, the predictions of demand and LOS we have made in collaboration with SBB are confidential.

\section{Literature Review}

The following review analyzes the literature on pedestrian flows in train stations in terms of three research dimensions that are relevant for this article: Data, models and applications. For an extensive literature review, the interested reader is referred to Daamen (2004) or Hänseler (2016) instead.

Data: Various forms of data have been collected in rail access facilities. These range from density and speed measurements for the estimation of density-speed relationships (Daly et al., 1991), to recordings of train arrival and departure times for the estimation of train delays (Higgins and Kozan, 1998), automated fare collection data to study pedestrian arrival time distributions, route choice and waiting times (van den Heuvel and Hoogenraad, 2014), capacity measurements of train doors to estimate access and egress times associated with public transport vehicles (Fernández et al., 2015), or pedestrian flow measurements obtained from CCTV networks (Ganansia et al., 2014). In most cases, typically only 
a single type of data is collected. Section 3 discusses such data types in detail, and Section 4 presents the available data for a case study of Lausanne railway station, representing a rich set of multiple data types.

Models: Fundamentally, two model types may be distinguished.

Demand estimation models are concerned with the assessment of the usage of a pedestrian facility. For instance, activity-based models consider demand as the result of an underlying need to perform activities, such as 'buying a ticket', or 'boarding a train' (Hoogendoorn and Bovy, 2004; Danalet, 2015). Another approach consists in estimating demand at the scale of origin-destination (OD) flows, such as 'North entrance to Platform \#5'. Lower computational cost and reduced data requirements make such estimators of $\mathrm{OD}$ demand viable for real-time applications and for large pedestrian networks. The problem of estimating OD demand has a long history in the context of road networks, for which link flow volumes and other indirect observations of demand are available (van Zuylen and Willumsen, 1980; Cascetta, 1984).

A second type of models is referred to as pedestrian traffic assignment models, which are useful for assessing the level-of-service (LOS) of pedestrian facilities. They typically consist of a route choice and a network loading model. Route choice models assign OD demand to routes, often using utility-based approaches (Borgers and Timmermans, 1986; Cheung and Lam, 1998; Hoogendoorn and Bovy, 2004). Network loading models describe the propagation of pedestrians along these routes. A multitude of suitable approaches have been proposed. These range from the well-known social force model (Helbing and Molnár, 1995) to cellular automata (Blue and Adler, 2001), queueing networks (Løvås, 1994), behavioral models (Robin et al., 2009) or continuum models (Hughes, 2002; Hoogendoorn et al., 2014).

The two model types, demand estimation and traffic assignment models, are complementary. For a given infrastructure and data, the demand estimation model takes the level-of-service as input and predicts the usage, whereas the traffic assignment model takes the usage as input, and predicts the level-of-service (see Fig. 1). The problem of estimating pedestrian OD demand in train stations is discussed in Section 5, whereas Section [6 considers a pedestrian traffic assignment model. 
Applications: In the literature, a large set of case studies involving pedestrian flows in train stations is available. These concern light rail and underground stations in Hong Kong (Lam et al., 1999; Lee et al., 2001), train stations in Lisbon and Bern (Hoogendoorn and Daamen, 2004; Rindsfüser and Klügl, 2007), a subway station in Paris (Kaakai et al., 2007), as well as further examples from Vienna, Beijing and Amsterdam (Seer et al., 2008; Jiang et al., 2009; Starmans et al., 2014). These case studies either consider the usage of rail access facilities (Nguyen et al., 1988; Wong and Tong, 1998; Montero et al., 2015), or its level-of-service (Hoogendoorn and Daamen, 2004; Rindsfüser and Klügl, 2007; van den Heuvel and Hoogenraad, 2014), but rarely both at the same time as in this work.

As for other transportation modes, assessment schemes for pedestrian facilities exist that allow to quantify the quality and comfort of pedestrian traffic. The corresponding literature is dominated by the seminal contribution by Fruin (1971), who proposes a density- and flow-based classification of level-of-service (LOS) considering six service levels. Density-based LOS indicators are useful both for walking and waiting areas, for which different thresholds apply. Flow-based indicators are used for walkways, escalators or stairways, and consider the specific flow, i.e., the flow per meter of width. Fruin's LOS classification schemes are widely used in practice, even though minor modifications have been made to consider national differences (Highway Capacity Manual, 2000; Brilon, 2001). The US-American standards, which are also applied in Switzerland, are further discussed in Section 6. Section 7 discusses the application of demand estimation and pedestrian traffic assignment models for infrastructure planning and dimensioning.

\section{Data sources}

Monitoring pedestrian traffic is difficult. First, the placement of sensors is challenging, as pedestrians can explore space freely, and are not confined to lanes. Second, the detection of pedestrians is an intricate task, as they can almost instantaneously stop or accelerate, and often travel in groups. Pedestrians are by nature heterogeneous, and their appearance depends on age, gender, or even trip purpose. Third, pedestrian traffic is highly 
variable, and sensors are required to capture a large range of traffic levels (U.S. Department of Transportation, 2013). Data availability is thus often limited in terms of its spatial or temporal coverage, or in terms of quality.

In the following, we provide a classification of data sources in five data types (see also Hänseler et al., 2015b), and discuss the importance of each data type for demand estimation and LOS assessment. For a discussion of sensing technologies as well as further practical guidance, we refer to the literature (Turner et al., 2007; Bauer et al., 2009; U.S. Department of Transportation, 2013).

OD flow data: Origin-destination (OD) trip tables represent the number of people traveling between each pair of origin and destination during predefined time intervals. The definition of $\mathrm{OD}$ areas depends on the layout of a train station, and may include platforms or platform sectors, shops, as well as entrance/exit areas. No distinction between 'intermediate' and 'final' destinations is made. If a pedestrian visits multiple destinations in a row, instead each intermediate trip is represented by an independent OD pair. A pedestrian may thus be associated with multiple OD trips. These OD trips are counted when the pedestrian leaves the respective origin.

OD flow data are obtained from pedestrian tracking systems, travel surveys, electronic tickets, or passive ICT sensors such as Bluetooth and WiFi scanners (Versichele et al., 2012; Alahi et al., 2013b; Kim et al., 2015). Due to their expensive collection, OD flow data are often not available for the entire network of interest (Bauer et al., 2009). Moreover, sampling is typically an issue, as in practice only a subset of pedestrians may be successfully detected. This holds in particular for ICT sensors, which capture only pedestrians carrying a corresponding device. Moreover, the temporal resolution is often low, with devices being detected only every couple of minutes (Danalet, 2015).

OD flow data are of particular importance for OD demand estimation, where they help to reduce the underdetermination that results if only indirect indicators of demand, such as link flows, are available (Cascetta et al., 1993). For LOS assessment, OD flows can also be useful if a traffic assignment model is available that allows to estimate LOS indicators.

Link flow data: Pedestrian infrastructures are often represented as a flow network, consisting of nodes and links. Links include in particular 
walkways or walkway sections, stairways, or escalators. By convention, 'link flow' refers to the inflow to a link, i.e., the flow that is measured at the origin of a link. Link flow data may be obtained from turnstiles, camera-based systems, infrared sensors or other detectors, including manual counting (Lee et al., 2001; Ton, 2014; Kim et al., 2015). Compared to OD flow data, the sensor technology for obtaining link flows are relatively mature, and the counting precision is high (U.S. Department of Transportation, 2013).

For OD demand estimation, link flow data represents the most common type of input data (Cascetta and Improta, 2002). As mentioned in the introduction, the efficient placement of sensors within a network is difficult, and widely discussed in the literature (Gentili and Mirchandani, 2012; Viti et al., 2014).

There are two ways of using link flow data for LOS assessment. Directly, by computing the flow per meter of width, and by comparing that to facility-specific thresholds (Fruin, 1971). For simple geometries, such as straight corridors with a constant width, this may be appropriate. A second way of using link flow data for LOS assessment is by using a traffic assignment model, applying it to the link of interest. The traffic assignment model then predicts densities and velocities, providing indirect information about the expected level of congestion.

Traffic condition data: Traffic condition data include measurements of density, walking speed, or walking times. Such observations are typically obtained from a pedestrian tracking system, or ICT sensors (Alahi et al., 2013b; Montero et al., 2015).

For the estimation of pedestrian OD demand, traffic condition data can be used as exogenous variables in the estimation process. For instance, Montero et al. (2015) use observed travel times to approximate the travel time distribution within a demand model. Alternatively, they can be used to indirectly validate the OD demand estimates, if the latter are combined with a traffic assignment model (see e.g. Djukic et al., 2015).

Traffic condition data are probably the most relevant source of information for LOS assessment. The most widely used LOS indicators are directly based on density and flow (Fruin, 1971).

Train timetable and ridership data: The train timetable has a significant impact on the usage of pedestrian facilities, both in terms of accumu- 
lation and in terms of flows. Fig. 2 provides a schematic representation of the most relevant types of flows that are influenced by the train timetable, namely boarding/alighting flows at train doors (solid arrows), as well as exit and access flows on platform access ways (dotted and dashed, respectively). A direct relationship between the train timetable and platform exit flows is established in Section 5,

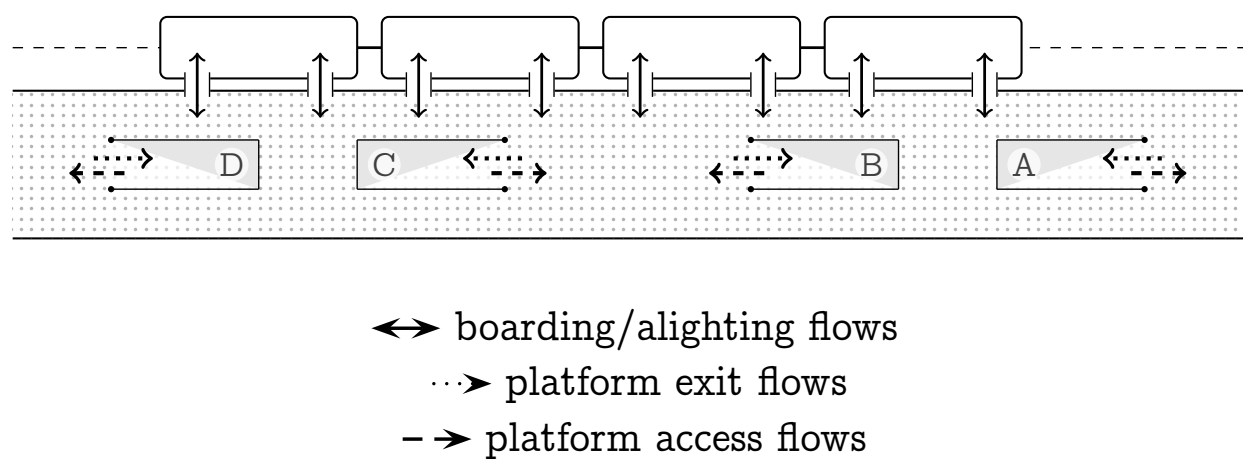

Figure 2: Train-induced flows on platforms and platform access ways.

If train delays are to be expected, the actual instead of the scheduled train timetable should be used. It may be obtained by observation, or from corresponding train delay models (Higgins and Kozan, 1998; Goverde, 2007). Particularly railway networks during peak periods or highly-interconnected timetables are prone to delays (Cule et al., 2011).

The number of boarding and alighting passengers per train may be obtained from door sensors, ticket sales, travel surveys, or approximated from the train capacity (Zhang et al., 2008; Kim et al., 2015; Fernández et al., 2015).

For OD demand estimation, the timetable and ridership information can be used to improve the accuracy of the estimate, or to provide a priori estimates when no other data is available (Hänseler et al., 2015b). In terms of LOS assessment, the number of boarding and alighting passengers is particularly useful for the dimensioning of platforms, which in practice is typically done using hydrodynamic models (Buchmüller and Weidmann, 2008).

Other demand data: Further information sources, such as sales or survey data, are sometimes available (Seneviratne and Morrall, 1985; Lee et al., 2001). These are typically useful for demand estimation, where 
they help narrowing the solution space. Video footage or a photographic documentation may be helpful for a qualitative level-of-service assessment (Helbing et al., 2002). Practical knowledge by the station operator regarding pedestrian dynamics, congested areas and the use of infrastructure in general may be a useful source of information as well.

Infrastructure data: Knowledge of the infrastructural layout is a prerequisite for both the estimation of demand and the level-of-service assessment. This typically includes the topology of pedestrian facilities, the location of access doors, ticket machines and shops, as well as the topology of the monitoring system, such as the location of Wi-Fi and Bluetooth access points, cameras, or counting systems.

The choice of sensors depends decisively on the desired information and the available budget. There is no single sensing technique that fits all purposes. Instead, often the simultaneous consideration of multiple data sources yields the most reliable results. For instance, the combination of Wi-Fi traces with a low temporal resolution and a strong sample bias with accurate, but spatially isolated count data may provide a good understanding of pedestrian flows. Further visual sensors may be helpful to assess pedestrian densities, and to quantify the prevailing level-of-service.

The cost of data collection depends on multiple factors, in particular on the already existing infrastructure. For instance, if a dense network of $\mathrm{Wi}-\mathrm{Fi}$ antennas is already available, it may be relatively cheap to collect Wi-Fi traces. If not, the installation of a power and data network, as well as of the Wi-Fi antennas themselves, may incur a significant cost. For optical sensors, such as tracking or count systems, the lighting conditions, height of the ceiling, requirements for protection from bad weather or vandalism, and many other factors may play a role.

\section{Case Study}

Lausanne railway station is the largest train station in the French-speaking part of Switzerland. Fig. 3 shows a schematic map of the station, encompassing nine rail tracks for passenger traffic (thin dashed lines). At its heart are two pedestrian underpasses (PUs), referred to as PU West and PU East (vertical corridors, indicated in the figure). Platforms are shown 
as dotted areas. Solid lines represent the walking network of the pedestrian facilities, and dashed curves represent corresponding network links that cannot be shown in the $2 \mathrm{D}$ scheme. $\mathrm{OD}$ areas are represented by labeled rectangles. Dark rectangles symbolize entrance/exit areas as well as service points within the train station. Rounded rectangles represent platform OD areas, i.e., platform sectors or entire platforms. Pedestrian count sensors are represented by diamonds. The shaded parts in the two pedestrian underpasses represent areas that are covered by a pedestrian tracking system.

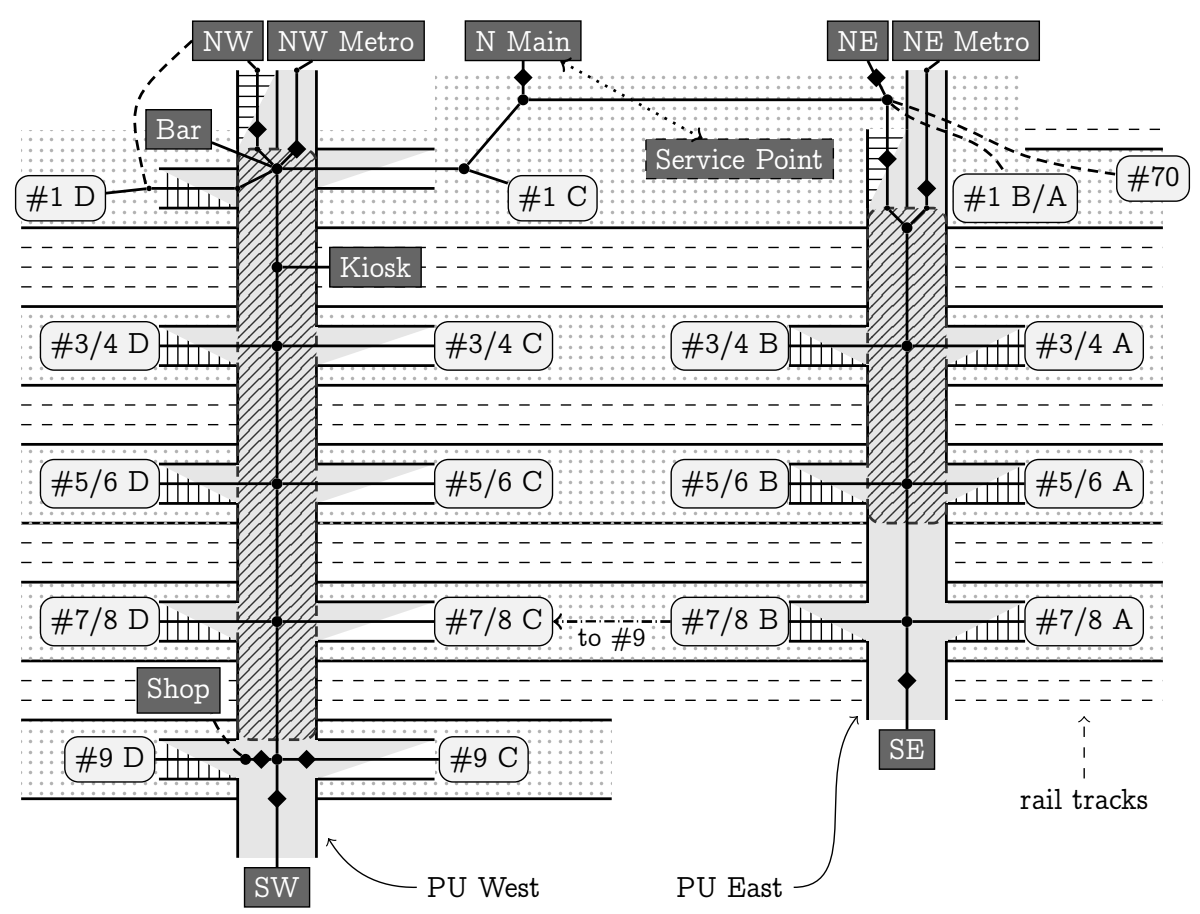

Figure 3: Lausanne railway station.

Using the classification presented in the previous section, the following data sources are available:

OD flow data: Subroute flows are available for the two pedestrian underpasses, in which a tracking system consisting of 60 sensors is installed. This sensor system allows to simultaneously track the trajectories of pedestrians across space and time. Details of the installation, as well as of the accuracy of observations, are described by Alahi et al. (2013b). 
Link flow data: Ten links of the pedestrian walking network, marked by diamonds in Fig. 3, are equipped with sensors that provide directed link counts with a resolution of one minute. To account for sensor saturation, observations are post-processed using a quadratic correction function (Ganansia et al., 2014).

Traffic condition data: Pedestrian trajectories obtained from the aforementioned tracking system allow to compute the prevailing speed, density and accumulation in pedestrian underpasses. Accumulation is defined as the number of pedestrians present in an area at a given point in time.

Train timetable and ridership data: The actual arrival and departure times and the assigned track are known for each train. An average estimate of boarding and alighting volumes is available from ticket sales data, within-train surveys, and infrared-based counts at train doors (Anken et al., 2012). These estimates date back to the year 2010 and are increased by $15 \%$ to reach the estimated level of the year 2013, which is considered in this article (Gendre and Zulauf, 2010). The boarding and alighting volumes are modeled as random normal variables with a standard deviation equal to $19.2 \%$ of their mean (Molyneaux et al., 2014).

Other demand data: For the sales points located in PU West (see Fig. 3), an estimate of the number of customer visits is available.

Infrastructure data: Detailed building plans containing the dimensions of all relevant pedestrian facilities, and the exact location of all parts of the monitoring system are available.

The usage of pedestrian facilities in Lausanne railway station is subject to recurring temporal patterns that are due to differences between weekdays/weekend, the day/night-rhythm, and a cyclic train timetable.

Fig. 4a shows the level of demand in the PUs over a typical working week, as measured by the pedestrian tracking system for the period between February 25 and May 19, 2013 (April 1 and 2 are excluded due to a sensor malfunctioning). Standard deviations are around $\pm 15,000$ pedestrians for a typical working day. 


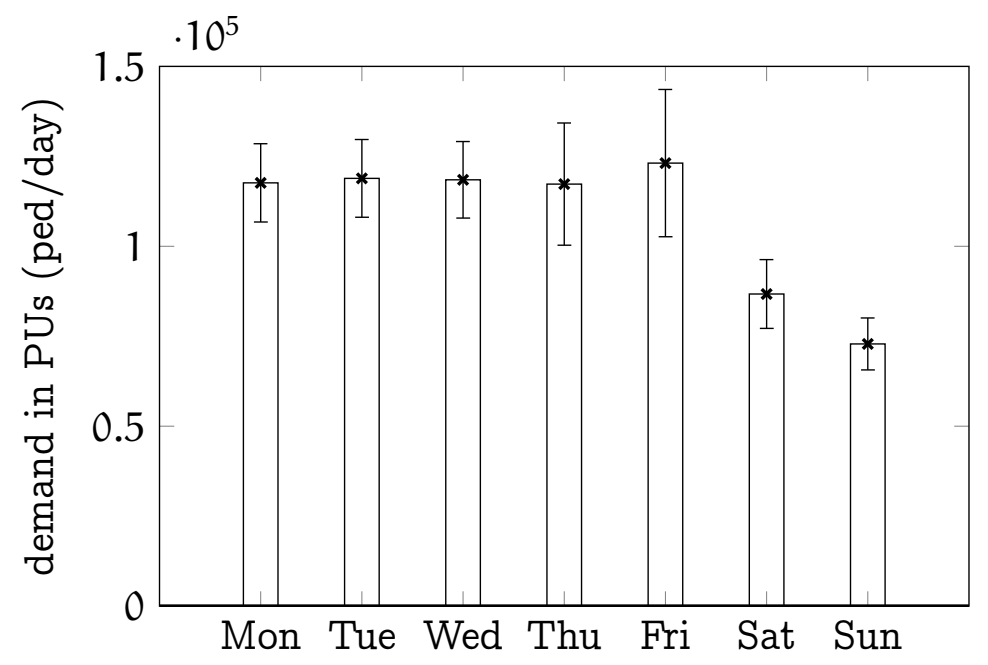

(a) Total number of visitors in pedestrian underpasses over a week

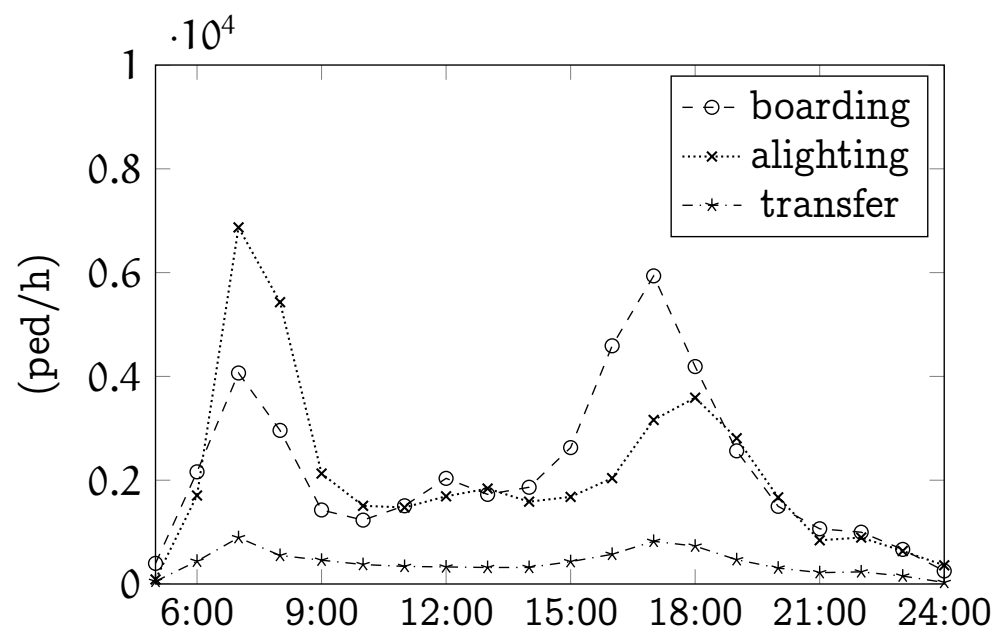

(b) Train passenger volume over a day

Figure 4: Observed demand in Lausanne railway station (year 2013).

The total number of pedestrian visits in the two pedestrian underpasses of Lausanne railway station (PU West and East) is slightly below $120,000 \mathrm{ped} /$ day on weekdays. This is in agreement with numbers reported by SBB, according to which there are in total about 140,000 station users per weekday, of which 98,000 are train users (Amacker, 2012). On Fridays, the station is busier than during the week due to weekly commuters returning to their principal place of residence, as well as due to weekend travelers. These additional passengers are spread around the evening peak 
period. The pedestrian demand on Saturdays and Sundays on the other hand is significantly lower. The shown pattern is similar to other major train stations in Switzerland, including in particular Basel, Bern and Zürich, which are serving up to four times as many passengers.

Fig. $4 \mathrm{~b}$ shows the evolution of train passengers during the course of a weekday. The shown data is obtained from semi-automatic travel surveys conducted in the year 2010, increased by $15 \%$ to approximate the demand in 2013 (Anken et al., 2012). It is distinguished between outgoing passengers (boarding), incoming passengers (alighting), and transfers, i.e., passengers that change train in Lausanne.

Between 7:00 and 8:00, the alighting volume (6,871 ped) is higher than the boarding volume (4,066 ped), whereas in the evening rush hour between 17:00 and 18:00, the number of boardings is higher (3,161 vs. 5,937 ped). According to these results, people come to Lausanne for work and leave the city again in the evening. The morning peak hour is shorter and busier than the evening peak hour, while the percentage of transfer passengers is just below $10 \%$ and nearly constant during the day. The bi-modal distribution of train passengers with a distinct peak in the morning and evening is typical for most train stations, with the exception of those that are primarily used for timed events such as concerts, or for touristic purposes.

A further analysis of the morning peak hour shows that the absolute peak over a weekday is reached between 07:35 and 7:50 (AM), when several long distance trains arrive and depart in close succession (Gendre and Zulauf, 2010). At this time of the day, more than 500 incoming users alight during a peak minute, whereas a few minutes later it can be less than a hundred per minute (Alahi et al., 2013a).

In the ensuing analysis, we consider the time period between 07:30 and 08:00 with a temporal aggregation of one minute. Data for a set of 10 'reference weekdays' is available, namely for January 22 and 23, February 6, 27 and 28, March 5, as well as April 9, 10, 18 and 30, 2013. These dates represent a set of typical weekdays (Tue, Wed, Thu) without major disruptions in the railway system, for which all of the aforementioned data sources are available.

Fig. $5 \mathrm{a}$ shows a scatter plot of accumulation vs. walking time along the main route in PU West, \#1C $\rightarrow \mathrm{SW}$. The data points represent 1,745 pedestrians. The accumulation is measured when a person enters PU West. The distribution of walking times is relatively wide, particularly at low values 


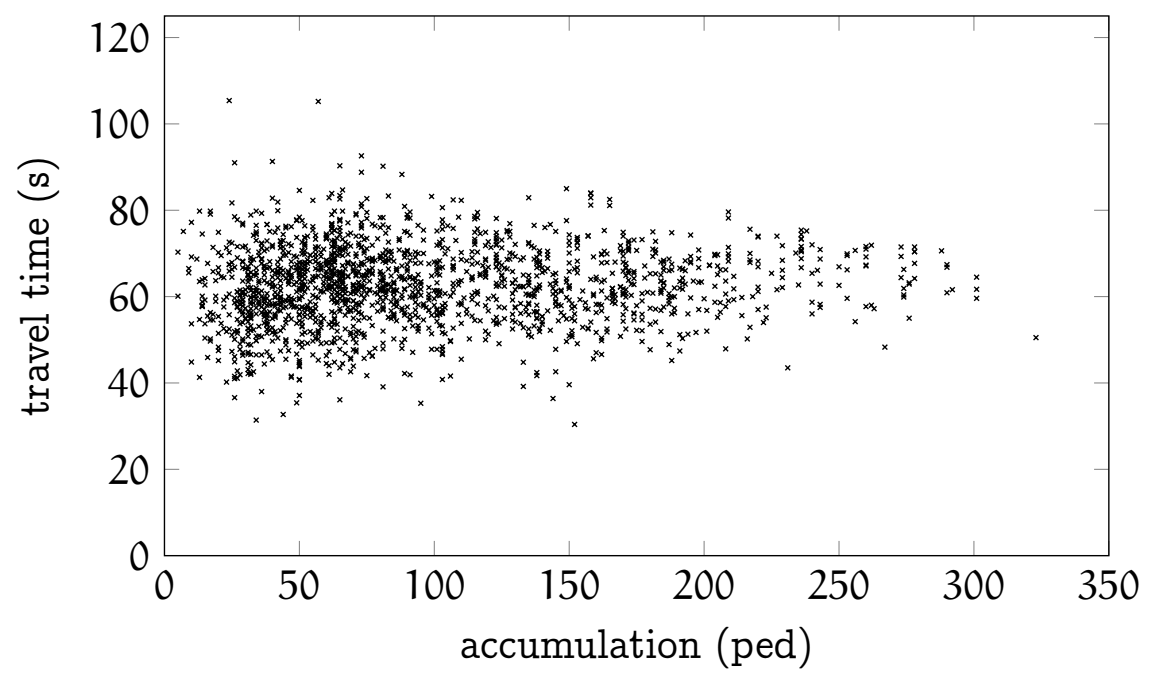

(a) Correlation between accumulation and walking time on route \#1C $\rightarrow$ SW

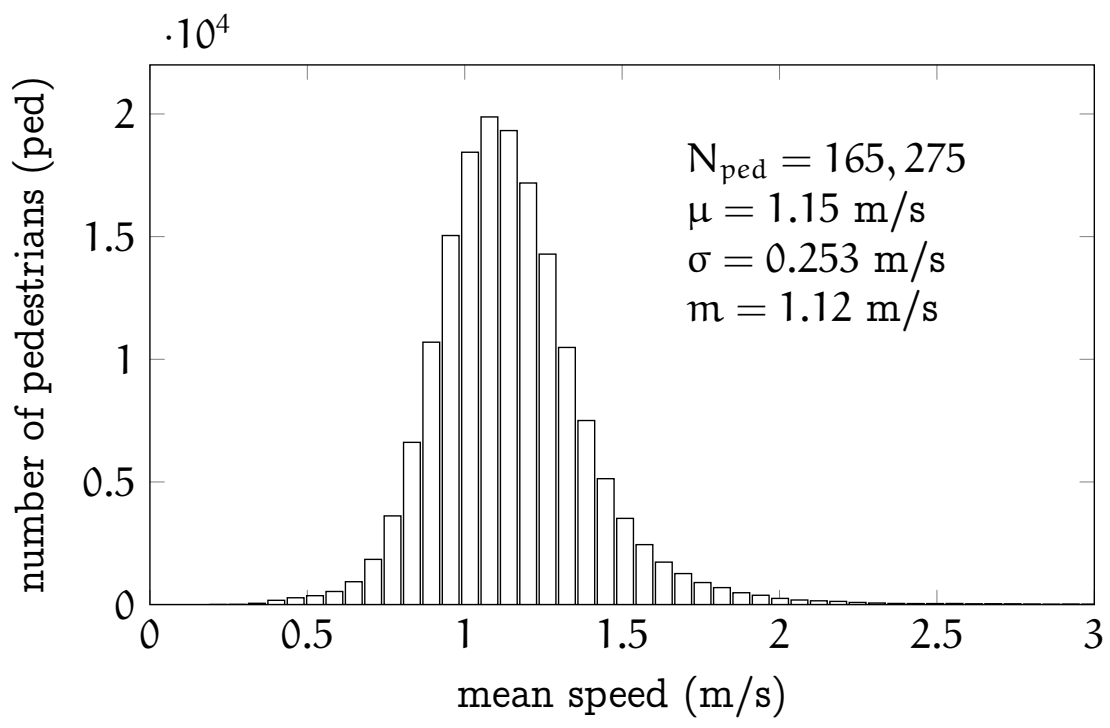

(b) Walking speed during morning peak hour in pedestrian underpasses

Figure 5: Walking times and walking speeds.

of accumulation. The mean walking times do not depend significantly on the accumulation, as would be the case if the facility were congested. This is an important finding for the demand estimation discussed in the next section, where data sources from different locations are combined. In the case of Lausanne railway station, the 'temporal distance' between sensors 
remains approximately constant across time, irrespective of the demand. It is unclear to what extent this finding can be generalized to other train stations. Presumably, it holds for most other train stations with a low to moderate level of congestion. For highly congested train stations, such as they are found in large cities, walking times are likely to depend on the prevailing densities.

Fig. 5b shows the walking speed distribution for a total of 165,275 pedestrians. The walking speed is computed from the ratio of traveled distance and walking time. A mean velocity of $1.15 \mathrm{~m} / \mathrm{s}$ is observed, and the median lies at $1.12 \mathrm{~m} / \mathrm{s}$. These values are in good agreement with the literature. For instance, Weidmann (1992) reports for the mean speed a range between $0.99 \mathrm{~m} / \mathrm{s}$ for tourists, up to $1.45 \mathrm{~m} / \mathrm{s}$ for business people. The spreading of the walking speed distribution is largely caused by differences in trip purpose, as well as by population heterogeneity in terms of age and gender. Other factors, such as time pressure, whether luggage is carried, or general health may also play a role.

\section{$5 \quad$ Estimation of origin-destination demand}

An explorative data analysis allows to identify the busiest time period and to accordingly reduce the estimation problem from a full day to a peak period. To obtain a comprehensive understanding of pedestrian demand during that period, the different data sources have to be 'combined' in an estimation framework. This is the focus of this section. For a mathematical description of the used OD demand estimation framework, the reader is referred to Hänseler et al. (2015b).

The problem of estimating OD demand consists in finding an estimate that, when applied to the pedestrian network of a train station, is most consistent with the corresponding train timetable, historical surveys, and all other data sources that are available (Cascetta and Improta, 2002). In the case of Lausanne railway station, all the aforementioned data sources are used with the exception of pedestrian trajectory data, which is considered for validation only.

In line with the introduction, we focus on the usage of walking facilities, and we take the train timetable explicitly into account. For that purpose, we concentrate on platform exit flows that are caused by alighting passen- 
gers of arriving trains. These are known to cause demand 'micro-peaks' that are critical for the dimensioning of rail access facilities (Hermant, 2012). Fig. 6a illustrates the typical pattern of platform exit flows (solid line), as well as a corresponding piecewise linear model that is derived from it (dash-dotted).

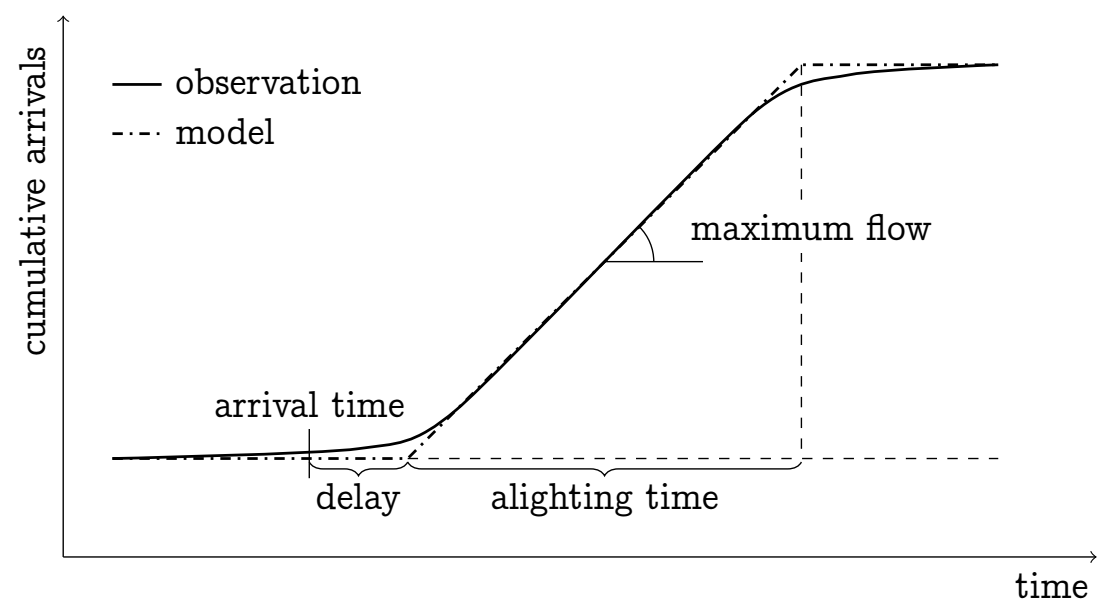

(a) Sample observation and piecewise linear model

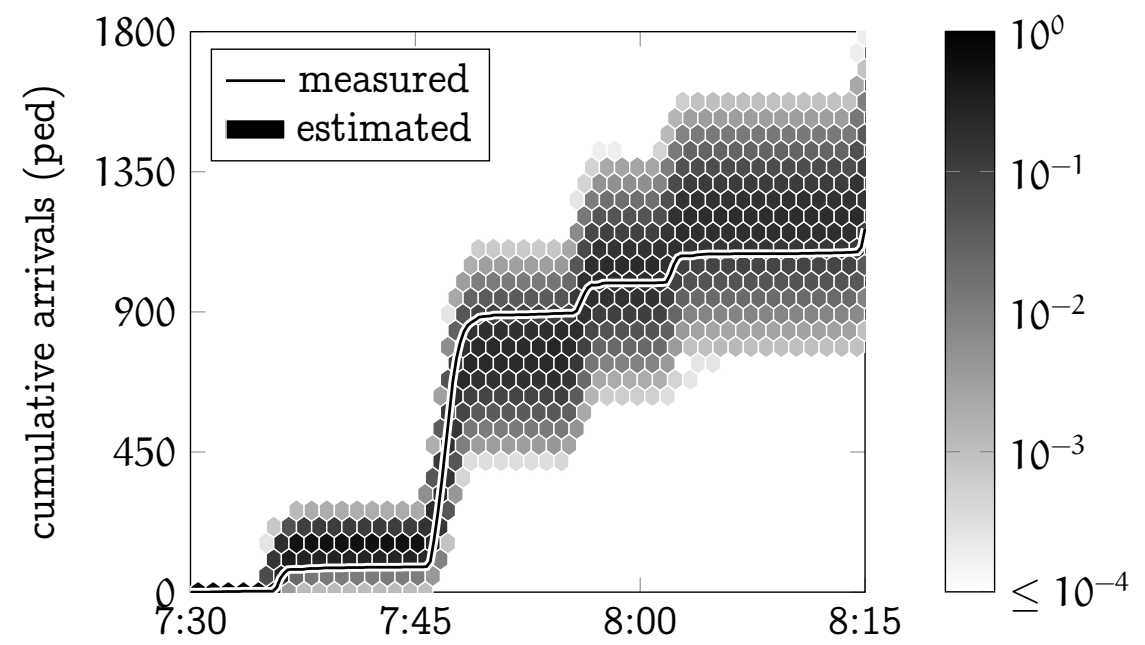

(b) Prediction and measurement for April 10, 2013 at platform \#5/6

Figure 6: Flow of alighting passengers on platform exit ways.

After the arrival of a train, a certain time elapses until the first pedestrians reach the platform exit ways. This may be due to the necessary 
walking to reach the exit ways, or a delay in the opening of doors after the train has stopped. Subsequently, a constant flow is established, whose magnitude is limited by the capacity of the exit ways. This assumption is based on empirical observations, showing that the exit ways typically represent the bottleneck in that situation (Benmoussa et al., 2011). Depending on the number of available exit ways, which often is determined by the position and length of a train, the magnitude of the flow may be different. Once all alighting passengers have left the access ways, the flow reaches again zero.

Due to various random effects, such as natural fluctuations in the ridership of a train, its position along a platform, or the distribution of passengers within a train, the parameters of the piecewise linear model are stochastic variables. The prediction of the model is then also stochastic, and may be represented by a probability band. In Fig. 6b, such a prediction band is shown for the exit flows from platform \#5/6, together with the actual measurement. The probability band represents the expected cumulative arrivals using a logarithmic probability density, and has been obtained from 7,500 Monte Carlo samplings. A good agreement between the prediction and the observation is found. The width of the band indicates that the variation in alighting volumes across days is relatively high.

If an appropriate specification of its parameters is available, this model can be applied to estimate the arrival flows on any platform. In the case of Lausanne railway station, such a parametrization is available, and traininduced exit flows can be predicted for all platforms (Molyneaux et al., 2014). These flows are used in the OD demand estimation framework, together with the available pedestrian counts and sales data. To associate the different information sources over space and time, a Normal walking speed distribution is assumed. The specifications for even walkways, inclined areas and stairways proposed by Weidmann (1992) are used.

The OD demand is jointly estimated for the 10-day reference set. Fig. 7 a provides a comparison of the estimated demand in the two pedestrian underpasses, and the corresponding observation obtained from the tracking system. The mean and standard deviation band are shown for both sources. Despite the strong and rapid fluctuations, the measured mean lies within the prediction band throughout the considered time horizon. In particular, the differences between the prediction and measurement for individual days are found to be smaller than the day-to-day variability observed in 
measurements of tracking data, which is used for validation only. Thus, at least for dimensioning purposes, the estimate of total demand can be considered accurate. Similar findings hold for the estimation of accumulation or OD flows (Hänseler et al., 2015b). In all cases, the integration of the train timetable is essential to reach such accuracy.

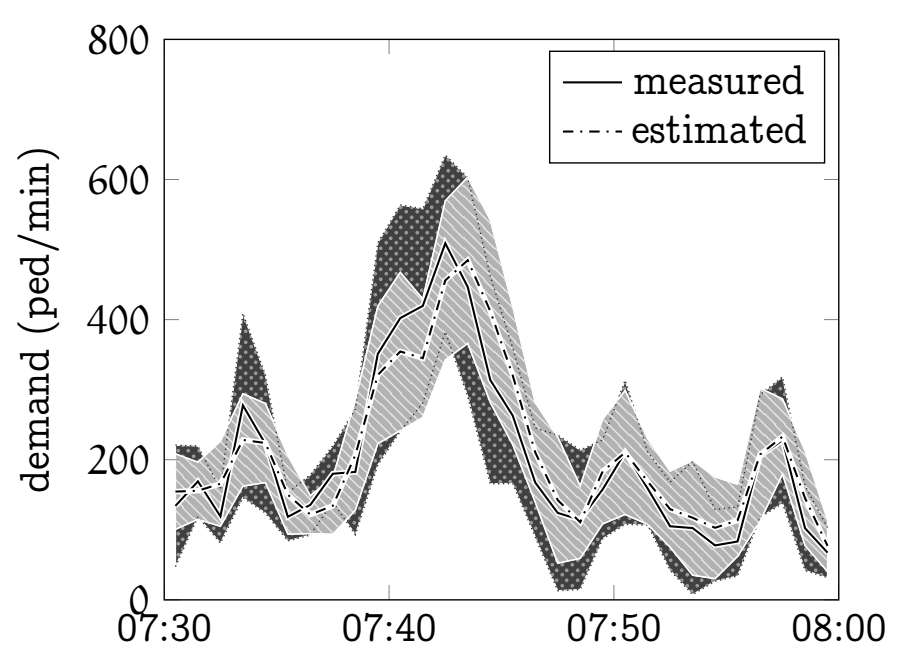

(a) Demand in PUs (MAE $=30.03$, RMSE $=37.56)$

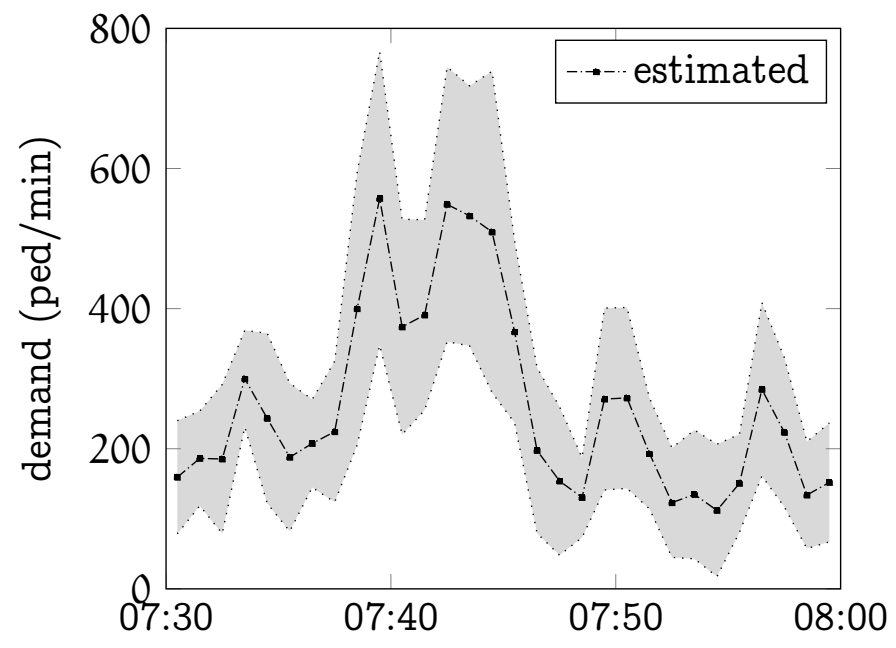

(b) Estimate of total demand in station

Figure 7: Estimated demand during morning peak hour.

In Fig. 7b, the estimated evolution of the total demand is provided, showing the mean and the standard deviation band. Both the withinday and the day-to-day variation (as indicated by the width of the deviation band) are significant. The average cumulative demand over the studied 30-min period amounts to 7,906 ped, representing about $8 \%$ of the daily station throughput (Amacker, 2012). The highest average demand is found between 7:39 and 7:40, where the overall demand rate amounts to $557.3 \mathrm{ped} / \mathrm{min}$. A quarter of an hour later, between 7:54 and 7:55, the mean demand reaches a minimum of $112.0 \mathrm{ped} / \mathrm{min}$. Within only a couple of minutes, the average demand thus varies by almost a factor of 5 . Such a periodical concentration is characteristic for the Swiss railway network that aims at bundling train arrivals and departures in order to minimize the waiting time of transfer passengers (SBB-Infrastruktur, 2013).

To consider the spatial distribution of demand, the latter may be aggregated over time. Fig. 8 shows a 'Circos' diagram of the average pedestrian OD demand (Krzywinski et al., 2009). Origin/destination areas are 
grouped into ten centroids, representing the train platforms \#1, \#3/4, $\# 5 / 6, \# 7 / 8, \# 9$ and \#70, the entrances North and South, the passageway to the metro, and a collection of shops. Light gray strips represent pedestrian flows emanating from train platforms, medium gray those originating at the entrance ways North and South as well as at the interface to the metro station, and dark gray strips pedestrian demand emanating from one of the sales points. For instance, one may read from the diagram that slightly more than 1,500 pedestrians arrive at platform \#5/6 during the considered 30-minute interval, of which more than a third are headed to the metro. During the same time interval, just below 1,500 pedestrians depart from the same platform, of which most access the train station from the North.

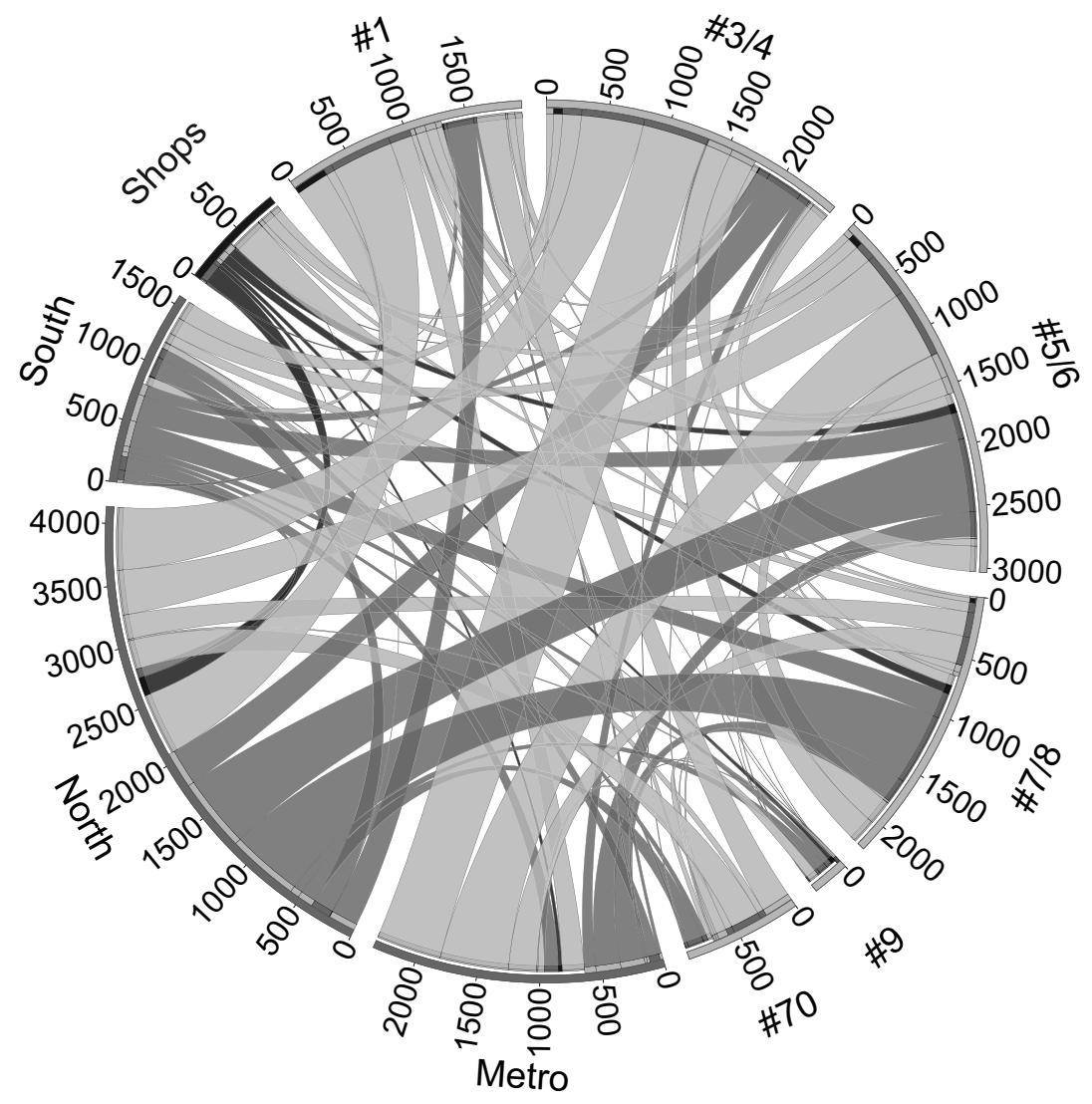

Figure 8: Pedestrian OD demand between 07:30 and 08:00. The origin of strips are color-coded as train platforms (light gray), city/metro/bus (medium gray) and shops (dark gray). 
Circos diagrams have originally been developed for studying genomes (Krzywinski et al., 2009), but turn out to be a powerful instrument for conveying the spatial structure of pedestrian OD demand to practitioners and authorities. They provide quantitative information of flow between any two centroids, which usually is difficult to represent in a single diagram. Moreover, the share of different user classes can be immediately perceived based on the different shadings. During the considered time period, $44.1 \%$ of all station visitors represent inbound passengers, $31.2 \%$ represent outbound passengers, $16.4 \%$ are transfer passengers, and the remaining pedestrians represent local users. These figures are different for each train station, and change between the morning, evening and off-peak periods.

A further way of visualizing demand is by means of network flows. Fig. 9 shows a map of the estimated minute-by-minute link flows for the time period between $7: 40$ and 7:48 on April 30, 2013. Here, the demand estimate of a specific day is chosen, as it allows to visualize the demand peaks caused by individual train arrivals and departures (see legend of Fig. 9). The shading of links represents the cumulative link flow over a minute in both directions. The diameter of nodes represents the minuteby-minute origin flow.

Between 7:44 and 7:45, a large number of pedestrians are present in most parts of the walking facilities, with flows exceeding 100 ped $/ \mathrm{min}$ on many links. The Western half of the train station is more active as several hundreds of passengers alight in sectors $\mathrm{C}$ and D (see also Fig. 3). Merely three minutes later, between $7: 47$ and $7: 48$, the train station is almost empty. Even the busiest links carry now less than $25 \mathrm{ped} / \mathrm{min}$. The total number of pedestrians has dropped by a factor of five.

Flow maps are useful to get an intuitive understanding of the spatiotemporal distribution of demand. They allow to see in a visually compelling way through which origin/destination area pedestrians are entering the station, and which links are most frequented at a given point in time. As such, circos diagrams and network flow maps are complementary.

\section{$6 \quad$ Pedestrian traffic assignment}

Despite its rich content of information, origin-destination demand reveals little about expected traffic conditions. To assess the level-of-service, the 


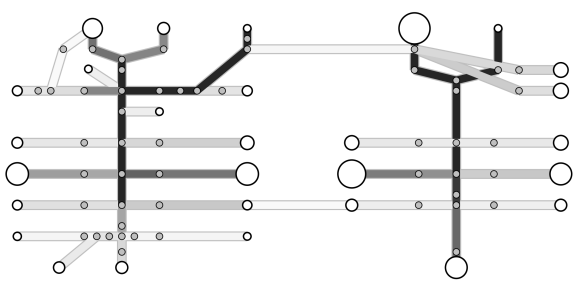

(a) 7:40-7:41

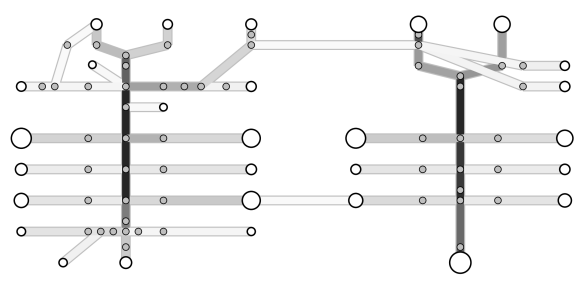

(c) $7: 42-7: 43$

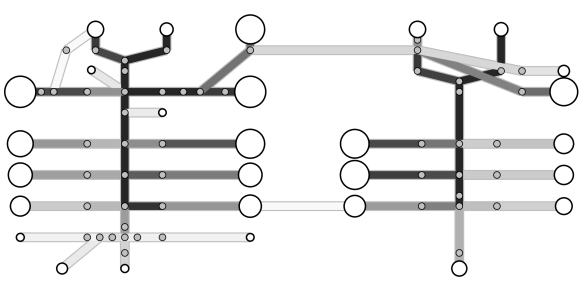

(e) $7: 44-7: 45$

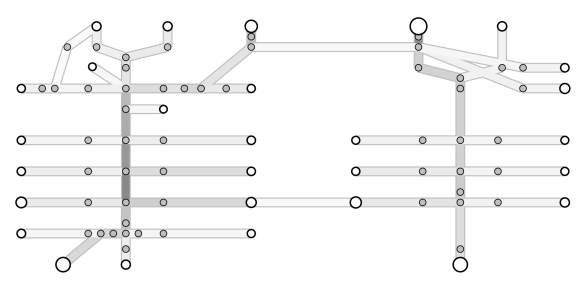

(g) $7: 46-7: 47$

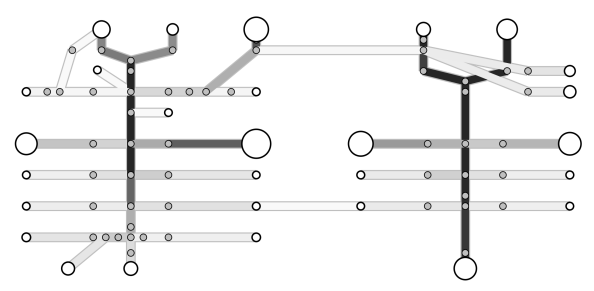

(b) 7:41-7:42

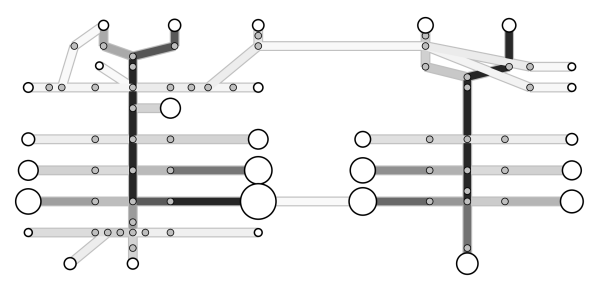

(d) 7:43-7:44

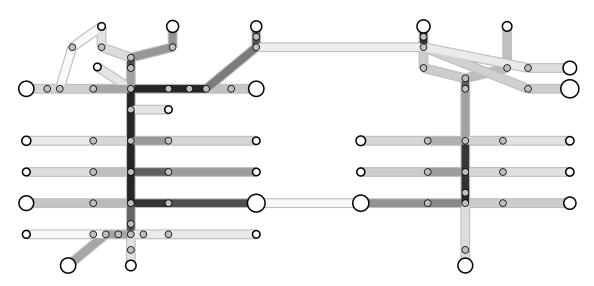

(f) $7: 45-7: 46$

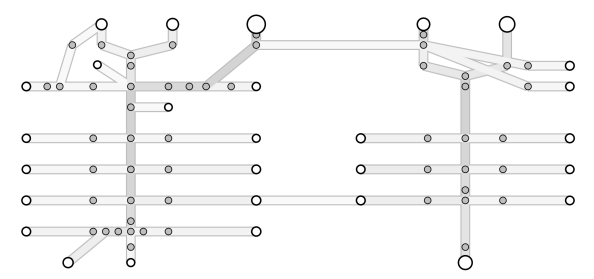

(h) $7: 47-7: 48$

○ $10 \mathrm{ped} / \mathrm{min} \bigcirc 100 \mathrm{ped} / \mathrm{min}$

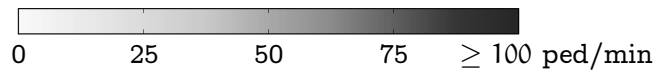

Figure 9: Pedestrian flow map between 07:40 and 07:48 on April 30, 2013. Between 7:40 and 7:41, the arrival of IR 1712 from Sion at 7:38:57 is discernible by the origin flow it creates on platform \#5/6. In the time period considered, this train is among those with the highest alighting volumes. During 7:41 and 7:42, the arrival of IR 1606 from Neuchâtel on track \#4 can be seen by the trace it leaves in the pedestrian flow map. Within less than a minute, IR 1710, IC 706 and IR 1407 arrive on platform \#7 at 7:42:24, platform \#5 at 7:42:59, and on platform \#3 at 7:43:18, respectively. Especially the former two represent major lines (from Brig and Zürich), causing large pedestrian movements. Their impact is visible in Fig. 9d and 9k. After the last arrival of a train, IR 2517 from Geneva arriving on platform \#1 at 7:44:37, pedestrian flows decay, as can be seen from Fig. 9g and 9h. 
interaction between infrastructural supply and demand needs to be taken into account.

For that purpose, a dynamic traffic assignment model is necessary. In the following, such a model is described and applied to investigate density levels in PU West, representing the busiest area in Lausanne railway station (see Fig. 9). A macroscopic modeling approach is pursued for several reasons. In particular, it allows for a quick implementation, as well as for an accurate calibration and physical interpretation of the obtained parameterization. These properties are useful for the presented level-of-service analysis, but become essential for planning, design or crowd management applications, where a fast and accurate modeling of pedestrian dynamics is key.

To obtain traffic conditions from the estimated OD demand, two steps are necessary. First, a route choice model is required to assign OD demand to route flows by specifying route split fractions. Any of the route choice models mentioned in the literature review may be used. In PU West, only a single route exists between each $O D$ pair, and computing these fractions is trivial. Second, a network loading model is needed to describe the propagation of pedestrians along these routes at the aggregate level.

We describe here a simple yet detailed network loading model. The focus is again on the presentation of the conceptual ideas. The reader interested in the mathematical specification is referred to Hänseler et al. (2014a).

Walkable space is partitioned into a set of areas as illustrated in Fig. 10a, where they are delimited by dotted lines. The shape and size of areas can be chosen freely. Typically, areas of approximately $10 \mathrm{~m}^{2}$ are used (Asano et al., 2007; Guo et al., 2011). A route is given by an origin and a destination, and a subset of areas (see shaded example in Fig. 10a). The choice of the actual sequence of areas within a route is up to the loading model. It is described at the aggregate level by means of turning proportions. These are such that pedestrians gradually approach their destination, avoiding areas of high density.

A pedestrian fundamental diagram governs the propagation of pedestrians across areas. Fig. $10 \mathrm{~b}$ shows the used density-speed relationship (solid curve), as well as the corresponding density-flow relationship that results in case of uni-directional motion (dashed curve). The functional form of these relationships is as proposed by Weidmann (1992), and the 


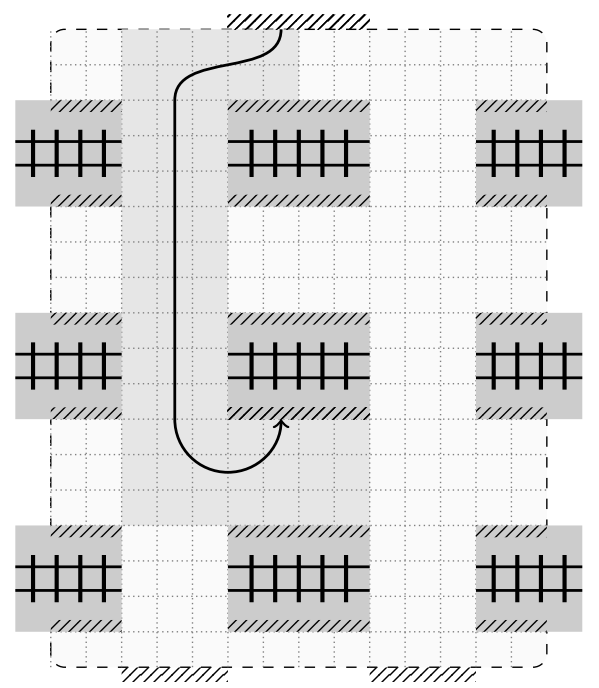

(a) Space decomposition

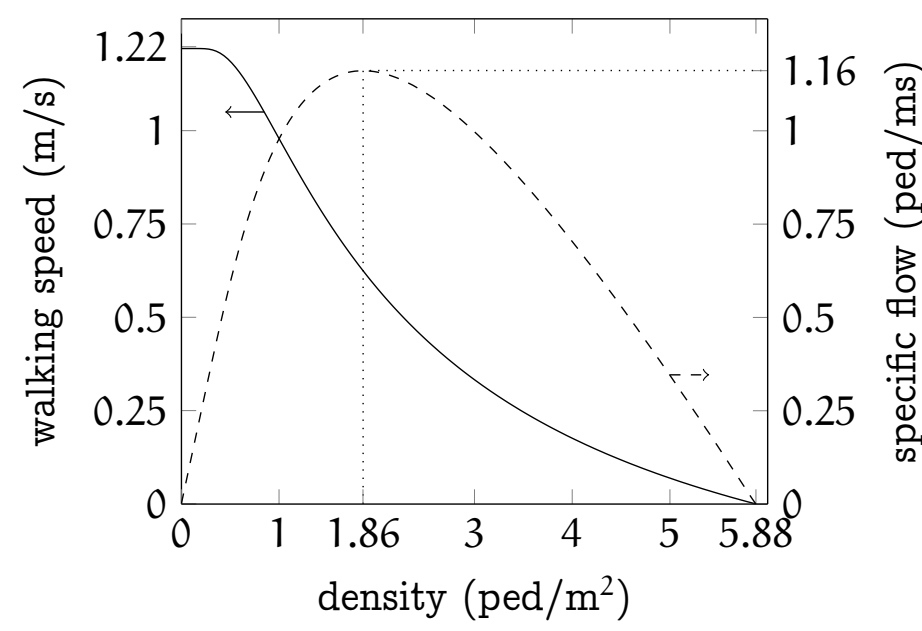

(b) Fundamental diagram

Figure 10: Network loading model.

parametrization is obtained from a calibration on trajectory data collected in Lausanne railway station in April 2013.

As can be seen from the density-flow relationship, the domain is split into a free-flow and a congested regime, with the transition at a density of $1.86 \mathrm{ped} / \mathrm{m}^{2}$. An increase in density in the free-flow regime leads to an increase in flow, whereas in the congested regime the opposite occurs. Such a behavior is typical for transportation networks, and applies both to vehicles and pedestrians (Greenshields et al., 1935). In practice, the exact density at which the transition occurs may vary, particularly depending on the prevailing flow pattern. For instance, in multi-directional flow, congested traffic conditions are typically reached at lower densities than in uni-directional flow (Weidmann, 1992). The reported value of $1.86 \mathrm{ped} / \mathrm{m}^{2}$ is thus of indicative value only.

For each area at given time intervals, the density is calculated, and based on the fundamental diagram, the corresponding flow is computed. It is thereby assumed that the walking speed within an area is the same in all directions, i.e., isotropy of walking speed is assumed. This is a fair assumption for mildly congested flows or those that are inherently uni-directional. In case of multi-directional flow at high densities, an anisotropic network loading model should be used (Lam et al., 2003; Hänseler et al., 2015a).

The density in areas can be directly used to assess the perceived com- 
fort and performance of a facility. The Highway Capacity Manual (HCM, Highway Capacity Manual, 2000) distinguishes six levels of service, ranging from LOS A (below $0.18 \mathrm{ped} / \mathrm{m}^{2}$, most favorable) to LOS F (above $1.33 \mathrm{ped} / \mathrm{m}^{2}$, least favorable). This classification is based on Fruin (1971), and represents a widely accepted standard. We note that only LOS F includes 'supercritical' densities, i.e., pedestrian densities greater than $1.86 \mathrm{ped} / \mathrm{m}^{2}$ that are associated with the congested regime (see Fig. 10b).

Fig. 11 shows the resulting level-of-service maps for January 22, 2013. For each time period of one minute, the model estimates and the corresponding measurement from pedestrian tracking data are shown.

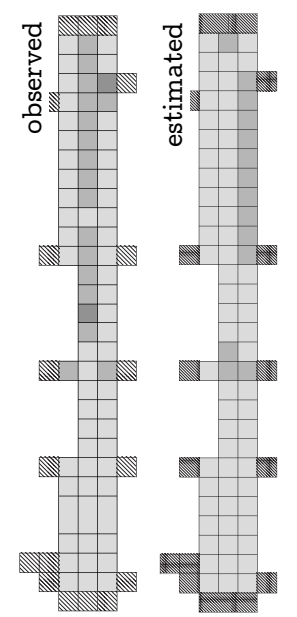

(a) 7:40-7:41

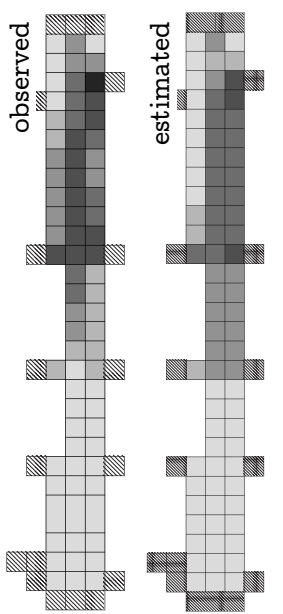

(b) $7: 41-7: 42$

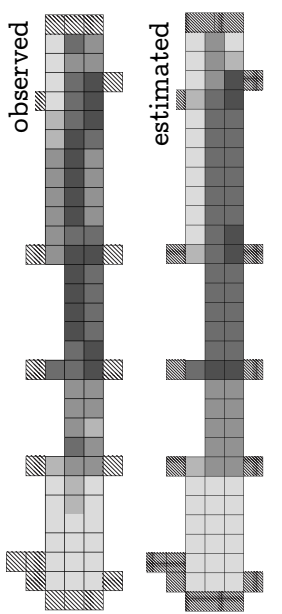

(c) $7: 42-7: 43$

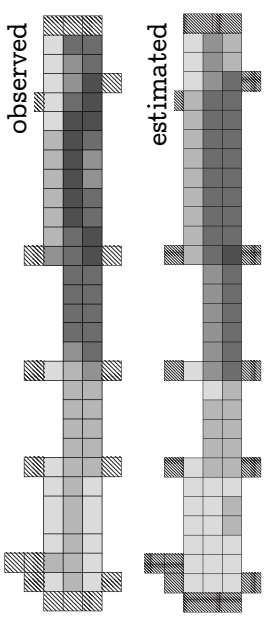

(d) 7:43-7:44

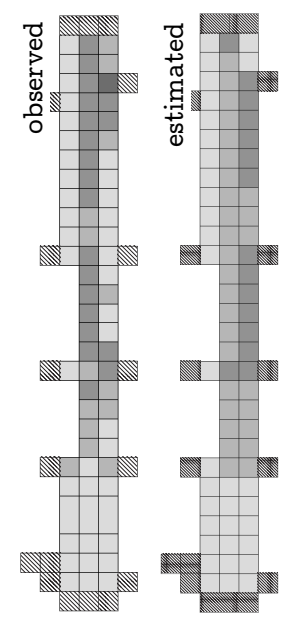

(e) $7: 44-7: 45$

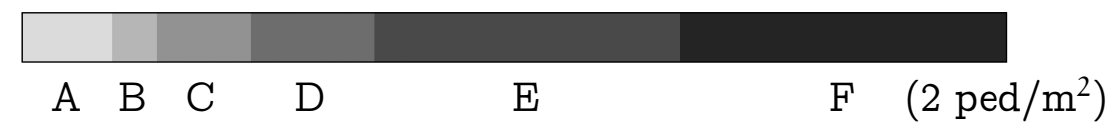

Figure 11: Level-of-service in PU West on January 22, 2013.

In the first time interval, the observed density map shows a high levelof-service, which is then reduced during the following minutes, before it recovers in the last interval. The dynamics with which pedestrian traffic evolves are remarkable, as is the fact that they can be accurately reproduced by the traffic assignment model. Certain differences between model prediction and observation may be found, for instance regarding the concentration of pedestrians along the centerline of the corridor. An analysis of several days shows however that these differences are small compared to the day-to-day variation in pedestrian traffic conditions. For the purposes 
considered in this work, i.e., for an assessment of the level-of-service that is sufficient for dimensioning, the estimates are considered to be of good quality. Moreover, a comparison to the social force model, which is the state-of-the-art in microscopic pedestrian flow modeling, shows that the performance of the proposed macroscopic model is equivalent or superior (Helbing and Molnár, 1995; Hänseler et al., 2014a).

The highest pedestrian densities are observed between 7:41 and 7:43, when various trains arrive. The level-of-service lies in the range between $A$ and $E$, i.e., densities are generally below $1.33 \mathrm{ped} / \mathrm{m}^{2}$. As is discussed in Section 7, according to Swiss standards LOS E should only be tolerated in bottlenecks, and not be present on wide walkways as in the case of PU West. The capacity of PU West is thus insufficient not only for the future, but already for the current demand.

To assess the required transfer times between connecting trains, walking times are of interest. Fig. 12 shows the walking time distribution in PU West as estimated by the traffic assignment model, and as observed in the trajectory data. Additionally, a Gaussian fit of the observed data is shown, revealing a mean walking time in PU West of $\mu=45.75 \mathrm{~s}$, and a standard deviation of $\sigma=11.72 \mathrm{~s}$. The agreement between observation and model prediction is generally satisfactory. Further analysis shows that this also holds for route-specific predictions of walking times, and in case of congestion (different case study, see Hänseler et al., 2014a).

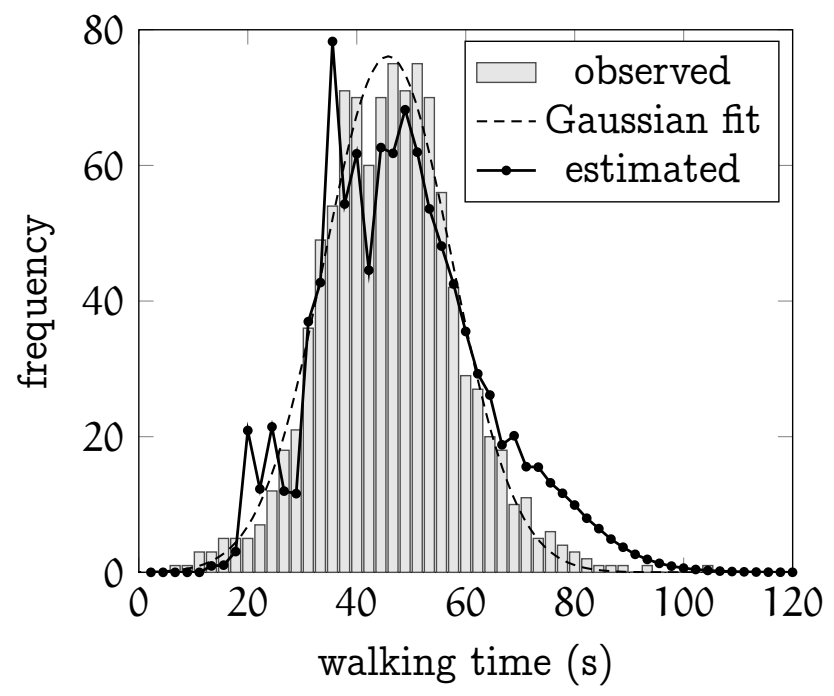

Figure 12: Walking time distribution for PU West $(\Delta t=2.22 \mathrm{~s})$. 
The area-based pedestrian traffic assignment model can thus be used to accurately predict the level-of-service in walking facilities of a train station. As before, no tracking data is necessary, of which only an independent data set has been used for calibration. Even if the model is calibrated solely based on values from the literature, its predictive quality is still good. This is due to the fact that the obtained parametrization is very similar to those of other researchers (see e.g. Weidmann, 1992).

\section{$7 \quad$ Planning guidelines}

In practice, the estimation of the current demand and level-of-service may be of interest, but typically does not represent the primary objective. More relevant is the consideration of future scenarios, which allow the assessment and optimization of construction plans, and thus the dimensioning of infrastructure facilities.

The configuration and dimensioning of pedestrian facilities in train stations is traditionally based on planning scenarios, such as 'passengers on platform awaiting boarding', 'flow of alighting passengers on platform exit ways', or 'transfer flows on pedestrian walkways' (Hoogendoorn and Daamen, 2004; Buchmüller and Weidmann, 2008; Zhang et al., 2008). In structural engineering, such scenarios are referred to as 'load cases'. An infrastructure is checked for serviceability against all the load cases it is likely to experience during its lifetime. In the context of rail access facilities, the load cases typically consider the arrival or departure of one or a few reference trains, and the resulting pedestrian OD demand is estimated using rules of thumb. The dimensioning is then done manually and separately for each facility element. This approach is notably pursued by the Highway Capacity Manual (2000) that provides individual worksheets for walkways, queueing areas and other types of facilities.

By using a computational framework to estimate demand and level-ofservice, the planning process of rail access facilities can be enhanced. First, due to the explicit integration of the train timetable, the use of individual load cases becomes obsolete. Second, the various facility elements can be dimensioned jointly, which allows to investigate their mutual influence on each other. The aim of this approach is however not to replace the aforementioned worksheets, but much more to complement them by additionally 
providing a more systemic perspective.

Based on our experience from Lausanne railway station, we suggest in the following a six-step process that is useful for the planning and dimensioning of pedestrian facilities in train stations, be it existing ones, or new stations. The approach is based on guidelines by Buchmüller and Weidmann (2008). The differences consist in (i) the direct consideration of the usage of a train station based on the timetable instead of indirectly through load cases, (ii) the use of a computer-based OD demand estimation framework instead of manual estimation techniques, and (iii) the use of a pedestrian traffic assignment model that allows to simultaneously dimension multiple facility elements. For each of the six steps, a short illustration at the example of Lausanne railway station is provided. The process may be iterative.

I. Traffic concept of train station. In a first step, the planning horizon is to be determined, as well as the corresponding operational concept for the expected peak periods. This includes the train timetable or line frequency, as well as the capacity and type of rolling stock. In Swiss train stations, typically the morning peak period on working days is critical, and in rare cases the evening peak hour. In particular cases, such as in touristic areas or for stations close to stadiums, certain periods on weekends or after mass events may be decisive for the dimensioning.

In a second step, a preliminary prediction of pedestrian OD demand can be made. This typically requires an analysis of the status quo, which serves to calibrate the demand estimator (see Section 5). Unless sufficient information is available, a data collection campaign may be required, involving for instance manual travel surveys, or the installation of flow sensors.

In the case of the on-going expansion of Lausanne railway station, the planning horizon is the year 2030, for which detailed information of the train timetable and rolling stock is available. The demand is 'expected to double for interregional trains, and to triple for regional trains' (Caillaud, 2011). To better understand the usage of the train station, a pedestrian tracking system has been installed. An exploratory data analysis, discussed in Section 4, shows that the critical period occurs indeed in the morning.

II. Functional requirements. The desired level-of-service needs to be specified, for instance for walkways, stairways, platforms or waiting areas. 
Typically, one of the standard LOS schemes is used, which rely on density or specific flow. In accordance with Swiss and US-norms (Weidmann, 1992; Highway Capacity Manual, 2000), it is typically required that LOS B or better be maintained for intervals of several minutes. During short intervals of up to a minute, LOS D is accepted. At bottlenecks, locally LOS E is still tolerated. Separate standards may apply under particular circumstances, such as after mass events. Maximal walking times can also be set, either based on a preliminary timetable that requires certain transfer times, or based on considerations related to comfort. The particular needs of disabled train users need to be taken into account, in accordance with the local legislation.

The placement of service and sales points needs to be discussed. Access to such facilities may increase the comfort and well-being of train station users, but at the same time compromise pedestrian traffic. The effect of the latter should be taken explicitly into account in the dimensioning of pedestrian facilities, both as far as available space is used and additional demand is induced. Generally, the more important a service, the higher its priority in the allocation of space should be, however without violating the pre-defined LOS standards.

In the case of Lausanne, maximum acceptable service levels are defined for platforms, ramps, stairways and horizontal walkways. The densitybased LOS schemes specified in the Highway Capacity Manual (2000) are used, with the thresholds as mentioned above (generally LOS B or better, for short intervals LOS D, LOS E exceptionally at bottlenecks). For the placement of sales and service points, the status quo is preserved.

III. Topology of pedestrian facilities. The network of pedestrian facilities is to be developed. This process takes into account (i) the surroundings of the train station, and in particular factors such as the connection to the local transportation system, the local network of walkways, points of attraction in the vicinity of the station, and workplace locations; (ii) existing buildings that are to be preserved, such as historical station halls or facilities that do not require a structural extension; and (iii) the track topology, which is either the existing one, or imposed by the design of the future rail network.

Subsequently, the type of facility elements and the connection between them can be specified. For vertical level changes, a choice between stair- 
ways, ramps, escalators, and elevators exists. Further facility elements that need to be specified include horizontal walkways, waiting areas and platforms. For each element, its position and characteristic dimensions (such as the length for walkways) are to be determined.

Once the topology of pedestrian facilities is specified accordingly, a preliminary assessment of walking distances may be made, verifying that the required transfer times are met. This should include the specific needs of people with reduced mobility. Generally, the topology should allow for short and direct connections between facilities.

For the planned extension of Lausanne railway station, the topology of pedestrian facilities is changed in that it incorporates a newly-built metro station for local transit, it directly connects to a museum complex to the northwest of the station, and in that it features three instead of two transversal pedestrian underpasses.

IV. Demand Prediction. An estimate of pedestrian demand is required. Using the framework discussed in Section 5, it can be obtained based on the traffic concept of the train station and the topology of pedestrian facilities. In the estimation process, the impact of congestion on demand is usually neglected. In principle, it would be possible to take that influence into account. However, it requires a joint application of the demand estimator and the traffic assignment model, as well as a detailed layout of facility elements, which is not available at this point. It would thus require a merging of demand estimation and dimensioning (see step V. below), which is cumbersome and rarely done in practice.

In the case of Lausanne, the influence of congestion is neglected in the estimation of demand. To obtain a prediction for the year 2030, the planned instead of the current timetable is used, and the ridership is increased based on available forecasts.

V. Dimensioning. Based on the network topology, a detailed dimensioning of facility elements is to be made. In this process, a traffic assignment model as described in Section 6 is useful. It quantitatively predicts the level-of-service that results for a given demand estimate as a function of the facility layout.

Thanks to a joint consideration of pedestrian facilities, a consistent layout is reached in which the dimensions are balanced across elements. 
This is crucial for instance for cross-sections of adjacent facilities, such as the width of walkways and stairways. In a second step, the placement of travel services and furniture, such as ticket machines, information panels, benches or mobile sales points can be considered. As a general rule, these should not obstruct the main paths that connect facility elements.

In certain areas of railway stations that are only lightly loaded, a dimensioning based on the resulting level-of-service may be inappropriate. Instead, standard values for cross-sections should be used. Corresponding specifications are often provided by national authorities that seek a minimum degree of comfort (Buchmüller and Weidmann, 2008).

In the case of Lausanne railway station, the development of the network topology and the dimensioning has been a highly iterative process. Several times, the number of pedestrian underpasses has been changed from two to three and vice versa. In the beginning, our mandate consisted mainly in determining an appropriate width of these transversal underpasses. However, it turned out that the main bottleneck is rather the connection between these transversal underpasses and lateral platform access ways. By 'smoothing' a previously rectangular layout, the level-of-service can be increased more significantly than by simply enlarging the width of pedestrian underpasses. This finding was only possible due to the joint consideration of the underpasses and their platform access ramps, and due to a realistic estimation of demand that yields multi-directional flow. In the literature, a similar example of smoothing a rectangular bottleneck is discussed by Helbing et al. (2001), who use an evolutionary algorithm to improve the design of pedestrian facility elements.

VI. Verification. Evidence is to be provided that the dimensioning fulfills the specified functional requirements, including the desired level-ofservice. Due to legal requirements, such a verification typically needs to be done manually (see e.g. worksheets in Highway Capacity Manual, 2000). Significant differences in national legislations exist in how such a verification is performed.

In the case of Lausanne railway station, we have provided recommendations regarding the dimensioning of the main walking facilities. However, we have not been involved in the finalization of the layout, nor in its legal verification. 


\section{Concluding remarks}

A framework for assessing the usage and level-of-service of rail access facilities has been discussed. It consists of a methodology for estimating pedestrian origin-destination demand based on the train timetable, and of a pedestrian traffic assignment model for estimating the resulting traffic conditions. The complete modeling framework is freely available (Hänseler et al., 2014b; Hänseler and Molyneaux, 2015).

Results from a case study of Lausanne railway station have shown that dynamic OD demand, level-of-service maps and walking time distributions can be accurately predicted. Required in that process are in particular the train timetable and ridership information.

The modeling framework has been embedded in a six-step planning process that is useful for practitioners and researchers confronted with the task of designing rail access facilities for a new train station to build, or an existing one to expand. This represents a powerful and innovative tool that can be used to complement more traditional, worksheet-based planning methods.

Besides planning applications, the framework can be used to develop practical and policy recommendations for station design, route signage, timetabling or train-track allocation. In the long term, applications involving crowd management can be envisaged, where pedestrian flows are observed and potentially controlled in real-time. Its aggregate nature, accuracy and computational efficiency make the presented framework highly suitable for that task.

\section{Acknowledgment}

We thank Bilal Farooq, Nicholas Molyneaux, Marija Nikolić and Michaël Thémans for their contributions. The research presented in this report has been conducted in the framework of 'PedFlux', a three-year research collaboration between EPFL's Transportation Center and SBB's rail access division (I-AT-BZU). Financial support by SBB-CFF-FFS and the Swiss National Science Foundation (SNSF grant \#200021-141099 'Pedestrian dynamics: flows and behavior') is thankfully acknowledged. We thank Serge P. Hoogendoorn, William H.K. Lam, Ulrich Weidmann, as well as two anonymous referees for most valuable comments. 


\section{References}

Alahi, A., Bagnato, L., Chanel, D., Alahi, A., 2013a. Technical report for SBB network of sensors. Tech. rep., VisioSafe SA, Switzerland.

Alahi, A., Ramanathan, V., Fei-Fei, L., 2013b. Socially-aware large-scale crowd forecasting. In: Proceedings of the IEEE Conference on Computer Vision and Pattern Recognition. pp. 2203-2210.

Amacker, K., 2012. SBB Facts and Figures. Annual report, Swiss Federal Railways (SBB-CFF-FFS), Bern, Switzerland.

Anken, N., Hänseler, F. S., Bierlaire, M., 2012. Flux piétonniers dans la gare de Lausanne: Vers l'estimation d'une matrice OD à l'aide des extrapolations voyageurs des CFF. Internal report (unpublished), Ecole Polytechnique Fédérale de Lausanne.

Asano, M., Sumalee, A., Kuwahara, M., Tanaka, S., 2007. Dynamic cell transmission-based pedestrian model with multidirectional flows and strategic route choices. Transportation Research Record: Journal of the Transportation Research Board 2039 (1), 42-49.

Bauer, D., Brändle, N., Seer, S., Ray, M., Kitazawa, K., 2009. Measurement of pedestrian movements: A comparative study on various existing systems. In: Timmermans, H. (Ed.), Pedestrian Behavior: Models, Data Collection and Applications. Emerald Group Publishing, Bingley, U.K.

Benmoussa, M., Ducommun, F., Khalfi, A., Kharouf, M., Koymans, A., Nguyen, M., Raies, A., Vidaud, M., Birchler, C., 2011. Analyse des flux piétonniers en gare de Lausanne. Tech. rep., Ecole Polytechnique Fédérale de Lausanne.

Blue, V. J., Adler, J. L., 2001. Cellular automata microsimulation for modeling bi-directional pedestrian walkways. Transportation Research Part B: Methodological 35 (3), 293-312.

Borgers, A., Timmermans, H., 1986. A model of pedestrian route choice and demand for retail facilities within inner-city shopping areas. Geographical analysis $18(2), 115-128$. 
Brilon, W., 2001. Handbuch für die Bemessung von Straßenverkehrsanlagen (HBS). Forschungsgesellschaft für Straßen und Verkehrswesen, Köln, Germany.

Buchmüller, S., Weidmann, U., 2008. Handbuch zur Anordnung und Dimensionierung von Fussgängeranlagen in Bahnhöfen. IVT Projekt Nr. C06-07. Institute for Transport Planning and Systems, ETH Zürich, Switzerland.

Caillaud, L., 2011. Extraction des données ASE/TL/Transitec. Presentation, Swiss Federal Railways (SBB-CFF-FFS), Lausanne, Switzerland.

Cascetta, E., 1984. Estimation of trip matrices from traffic counts and survey data: A generalized least squares estimator. Transportation Research Part B: Methodological 18 (4), 289-299.

Cascetta, E., Improta, A. A., 2002. Estimation of travel demand using traffic counts and other data sources. Applied Optimization 63, 71-91.

Cascetta, E., Inaudi, D., Marquis, G., 1993. Dynamic estimators of origindestination matrices using traffic counts. Transportation Science 27 (4), 363-373.

Cheung, C. Y., Lam, W. H. K., 1998. Pedestrian route choices between escalator and stairway in MTR stations. Journal of Transportation Engineering 124 (3), 277-285.

Chung, C. Y., 2012. KORAIL - Changing People's Lifestyle. Newspaper article, Business Korea, South Korea.

Cule, B., Goethals, B., Tassenoy, S., Verboven, S., 2011. Mining train delays. In: Advances in Intelligent Data Analysis X. Springer, pp. 113-124.

Daamen, W., 2004. Modelling passenger flows in public transport facilities. Ph.D. thesis, Delft University of Technology.

Daly, P. N., McGrath, F., Annesley, T. J., 1991. Pedestrian speed/flow relationships for underground stations. Traffic Engineering \& Control 32 (2), 75-78.

Danalet, A., 2015. Activity choice modeling for pedestrian facilities. Ph.D. thesis, Ecole Polytechnique Fédérale de Lausanne. 
Djukic, T., Barceló, J., Bullejos, M., Montero, L., Cipriani, E., van Lint, H., Hoogendoorn, S. P., 2015. Advanced traffic data for dynamic od demand estimation: The state of the art and benchmark study. In: 94th Annual Meeting of the Transportation Research Board, Washington, USA, 11-15 January 2015.

Fernández, R., Valencia, A., Seriani, S., 2015. On passenger saturation flow in public transport doors. Transportation Research Part A: Policy and Practice 78, 102-112.

Fruin, J. J., 1971. Pedestrian planning and design. Metropolitan Association of Urban Designers and Environmental Planners, Michigan, USA.

Ganansia, F., Carincotte, C., Descamps, A., Chaudy, C., 2014. A promising approach to people flow assessment in railway stations using standard CCTV networks. In: Transport Research Arena, Paris, France.

Gendre, G., Zulauf, C., 2010. Gare de Lausanne: Analyse des flux piétonniers. Internal report (I-PM-LS; unpublished), Swiss Federal Railways (SBB-CFF-FFS), Lausanne, Switzerland.

Gentili, M., Mirchandani, P. B., 2012. Locating sensors on traffic networks: Models, challenges and research opportunities. Transportation Research Part C: Emerging Technologies 24, 227-255.

Goverde, R. M. P., 2007. Railway timetable stability analysis using maxplus system theory. Transportation Research Part B: Methodological 41 (2), 179-201.

Greenshields, B., Bibbins, J. R., Channing, W. S., Miller, H. H., 1935. A study of traffic capacity. In: Highway research board proceedings. Vol. 1935. National Research Council (USA), Highway Research Board.

Guo, R. Y., Huang, H. J., Wong, S. C., 2011. Collection, spillback, and dissipation in pedestrian evacuation: A network-based method. Transportation Research Part B: Methodological 45 (3), 490-506.

Hänseler, F. S., 2016. Modeling and estimation of pedestrian flows in train stations. Ph.D. thesis, Ecole Polytechnique Fédérale de Lausanne. 
Hänseler, F. S., Bierlaire, M., Farooq, B., Mühlematter, T., 2014a. A macroscopic loading model for time-varying pedestrian flows in public walking areas. Transportation Research Part B: Methodological 69, 60-80.

Hänseler, F. S., Lam, W. H. K., Bierlaire, M., Lederrey, G., Nikolić, M., 2015a. A dynamic network loading model for anisotropic and congested pedestrian flows. TRANSP-OR Report Nr. 151026, Ecole Polytechnique Fédérale de Lausanne.

Hänseler, F. S., Molyneaux, N. A., 2015. Python implementation of pedestrian OD demand estimator for train stations.

URL https://github.com/flurinus/DemEstMeth

Hänseler, F. S., Molyneaux, N. A., Bierlaire, M., 2015b. Estimation of pedestrian origin-destination demand in train stations. TRANSP-OR Report Nr. 150703, Ecole Polytechnique Fédérale de Lausanne.

Hänseler, F. S., Mühlematter, T., Farooq, B., 2014b. Java implementation of PedCTM.

URL https://github.com/flurinus/PedCTM

Helbing, D., Farkas, I., Molnar, P., Vicsek, T., 2002. Simulation of pedestrian crowds in normal and evacuation situations. Pedestrian and evacuation dynamics 21 .

Helbing, D., Molnár, P., 1995. Social force model for pedestrian dynamics. Physical Review E 51 (5), 4282-4286.

Helbing, D., Molnar, P., Farkas, I. J., Bolay, K., 2001. Self-organizing pedestrian movement. Environment and Planning B 28 (3), 361-384.

Hermant, L. F. L., 2012. Video data collection method for pedestrian movement variables \& development of a pedestrian spatial parameters simulation model for railway station environments. Ph.D. thesis, Stellenbosch University.

Higgins, A., Kozan, E., 1998. Modeling train delays in urban networks. Transportation Science 32 (4), 346-357.

Highway Capacity Manual, 2000. Transportation Research Board. Washington, DC. 
Hoogendoorn, S. P., Bovy, P. H. L., 2004. Pedestrian route-choice and activity scheduling theory and models. Transportation Research Part B: Methodological 38 (2), 169-190.

Hoogendoorn, S. P., Daamen, W., 2004. Design assessment of Lisbon transfer stations using microscopic pedestrian simulation. In: Computers in railways IX (Congress Proceedings of CompRail 2004). pp. 135-147.

Hoogendoorn, S. P., van Wageningen-Kessels, F. L. M., Daamen, W., Duives, D. C., 2014. Continuum modelling of pedestrian flows: From microscopic principles to self-organised macroscopic phenomena. Physica A: Statistical Mechanics and its Applications 416, 684-694.

Hughes, R. L., 2002. A continuum theory for the flow of pedestrians. Transportation Research Part B: Methodological 36 (6), 507-535.

Jiang, C. S., Deng, Y. F., Hu, C., Ding, H., Chow, W. K., 2009. Crowding in platform staircases of a subway station in China during rush hours. Safety Science 47 (7), 931-938.

Kaakai, F., Hayat, S., El Moudni, A., 2007. A hybrid Petri nets-based simulation model for evaluating the design of railway transit stations. Simulation Modelling Practice and Theory 15 (8), 935-969.

Kallas, S., 6 2014. Railways: Paving the way for more growth, more efficiency and service quality in Europe. Press release 14, European Commission for Transport, Brussels, Belgium.

Kasparick, U., 2010. Mobilität in Deutschland 2008: Ergebnisbericht. PN 3849/FE-Nr. 70.801/2006. Bundesministerium für Verkehr, Bau und Stadtentwicklung, Berlin, Germany.

Kim, K. M., Hong, S. P., Ko, S. J., Kim, D., 2015. Does crowding affect the path choice of metro passengers? Transportation Research Part A: Policy and Practice 77, 292-304.

Krzywinski, M., Schein, J., Birol, İ., Connors, J., Gascoyne, R., Horsman, D., Jones, S. J., Marra, M. A., 2009. Circos: an information aesthetic for comparative genomics. Genome research 19 (9), 1639-1645. 
Lam, W. H. K., Cheung, C. Y., Lam, C. F., 1999. A study of crowding effects at the Hong Kong light rail transit stations. Transportation Research Part A: Policy and Practice 33 (5), 401-415.

Lam, W. H. K., Lee, J., Chan, K. S., Goh, P. K., 2003. A generalised function for modeling bi-directional flow effects on indoor walkways in Hong Kong. Transportation Research Part A: Policy and Practice 37 (9), 789-810.

Lee, J. Y. S., Lam, W. H. K., Wong, S. C., 2001. Pedestrian simulation model for Hong Kong underground stations. In: Intelligent Transportation Systems. IEEE, pp. 554-558.

Løvås, G. G., 1994. Modeling and simulation of pedestrian traffic flow. Transportation Research Part B: Methodological 28 (6), 429-443.

LTA Singapore, 2012. Singapore: Average daily public transport ridership (1995-2011), published on www.globalmasstransit.net.

Molyneaux, N. A., Hänseler, F. S., Bierlaire, M., 2014. Modeling of traininduced pedestrian flows in railway stations. In: Proceedings of the 14th Swiss Transport Research Conference. Locarno, Switzerland.

Montero, L., Codina, E., Barceló, J., 2015. Dynamic od transit matrix estimation: formulation and model-building environment. In: Progress in Systems Engineering. Springer, Berlin, Germany, pp. 347-353.

Nguyen, S., Morello, E., Pallottino, S., 1988. Discrete time dynamic estimation model for passenger origin/destination matrices on transit networks. Transportation Research Part B: Methodological 22 (4), 251-260.

Nio, I., 2012. Het station als publieke ruimte (in Dutch). Tech. rep., Bureau Spoorbouwmeester, Amsterdam, The Netherlands.

Parkinson, T., Fisher, I., 1996. Rail transit capacity. Vol. 13. Transportation Research Board, National Research Council, Washington, DC.

Puentes, R., Tomer, A., Kane, J., 2013. A new alignment: Strengthening America's commitment to passenger rail. Brookings Institution Press, Washington, DC. 
Rindsfüser, G., Klügl, F., 2007. Agent-based pedestrian simulation: A case study of Bern Railway Station. The Planning Review 170, 9-18.

Robin, T., Antonini, G., Bierlaire, M., Cruz, J., 2009. Specification, estimation and validation of a pedestrian walking behavior model. Transportation Research Part B: Methodological 43 (1), 36-56.

SBB-Infrastruktur, 2013. Le processus de l'élaboration de l'horaire. Internal report (unpublished), Swiss Federal Railways (SBB-CFF-FFS), Bern, Switzerland.

Schneider, J., 2012. Network condition report 2012. Annual report, Swiss Federal Railways (SBB-CFF-FFS), Bern, Switzerland.

Seer, S., Bauer, D., Brandle, N., Ray, M., 2008. Estimating pedestrian movement characteristics for crowd control at public transport facilities. In: Intelligent Transportation Systems. IEEE, pp. 742-747.

Seneviratne, P. N., Morrall, J. F., 1985. Analysis of factors affecting the choice of route of pedestrians. Transportation Planning and Technology 10 (2), 147-159.

Starmans, M., Verhoeff, L., van den Heuvel, J. P. A., 2014. Passenger transfer chain analysis for reallocation of heritage space at Amsterdam Central station. Transportation Research Procedia 2, 651-659.

Ton, D., 2014. NAVISTATION: A study into the route and activity location choice behaviour of departing pedestrians in train stations. Master's thesis, Delft University of Technology.

Turner, S., Middleton, D., Longmire, R., Brewer, M., Eurek, R., 2007. Testing and evaluation of pedestrian sensors. Monograph, Texas Transportation Institute, Texas A\&M University.

U.S. Department of Transportation, 2013. Traffic monitoring guide. Tech. rep., Federal Highway Administration.

van den Heuvel, J. P. A., Hoogenraad, J. H., 2014. Monitoring the performance of the pedestrian transfer function of train stations using automatic fare collection data. Transportation Research Procedia 2, 642-650. 
van Zuylen, H. J., Willumsen, L. G., 1980. The most likely trip matrix estimated from traffic counts. Transportation Research Part B: Methodological 14 (3), 281-293.

Versichele, M., Neutens, T., Delafontaine, M., Van de Weghe, N., 2012. The use of Bluetooth for analysing spatiotemporal dynamics of human movement at mass events: A case study of the Ghent Festivities. Applied Geography 32 (2), 208-220.

Viti, F., Rinaldi, M., Corman, F., Tampère, C. M. J., 2014. Assessing partial observability in network sensor location problems. Transportation Research Part B: Methodological 70, 65-89.

Weidmann, U., 1992. Transporttechnik der Fussgänger. Schriftenreihe des IVT Nr. 90. Institute for Transport Planning and Systems, ETH Zürich, Switzerland.

Wong, S. C., Tong, C., 1998. Estimation of time-dependent origindestination matrices for transit networks. Transportation Research Part B: Methodological 32 (1), 35-48.

Zhang, Q., Han, B., Li, D., 2008. Modeling and simulation of passenger alighting and boarding movement in Beijing metro stations. Transportation Research Part C: Emerging Technologies 16 (5), 635-649. 